Research Article

\title{
Research on the Deformation Mechanism of Mining Roadway Stratiform Surrounding Rock with Nonuniform Stress Field
}

\author{
Yongxin Sun (iD) ${ }^{1,2}$ \\ ${ }^{1}$ School of Mines, China University of Mining and Technology, Xuzhou 221116, Jiangsu, China \\ ${ }^{2}$ Shanxi Tiandi Wangpo Coal Mining Co.,Ltd., Jincheng, Shanxi 048021, China \\ Correspondence should be addressed to Yongxin Sun; vipsunyongxin@163.com
}

Received 18 December 2020; Revised 27 January 2021; Accepted 5 February 2021; Published 25 February 2021

Academic Editor: Miao Chen

Copyright $\odot 2021$ Yongxin Sun. This is an open access article distributed under the Creative Commons Attribution License, which permits unrestricted use, distribution, and reproduction in any medium, provided the original work is properly cited.

\begin{abstract}
Aiming at the failure problems of mining roadway stratiform surrounding rock influenced by asymmetrical high stress, firstly, the rock instability conditions of different structural plane angles were summarized based on the mechanical model of rock joints and instability criterion. Secondly, stresses, plastic zone, and displacement of surrounding rock with different structural plane angles were calculated and analyzed with the theoretical calculation method or numerical simulation method, respectively. The distribution characteristics of plastic zone of surrounding rock under different influence factors are further studied, and the results show that the lateral pressure coefficient can change the size and shape of plastic zone at the same time. The damage mechanism was analyzed through the above study. Research studies show that the shear and tension failure area of plastic zone were directly determined by the maximum shear stress and the minimum principal stress. The effect of structure planes on stress has two sides, one to destroy the continuity and the other to strengthen discreteness and laddering nature. When the angle between maximum shear stress and structure plane increases, the extended mode and distribution pattern of plastic zone change substantially as well. The \#15 haulage roadway is taken as engineering background, and the above research's results are verified by the comprehensive analysis. The research results can enrich the butterfly plastic zone theory and provide the basis for roadway supporting design.
\end{abstract}

\section{Introduction}

In the process of coal mining, the surrounding rock of the roadway is almost all layered rock, and the deformation and failure of the surrounding rock of the roadway have always been paid attention to by many experts and scholars $[1,2]$. Layered surrounding rocks include rock and bedding plane, whose physical and mechanical properties have an important impact on the deformation and failure of surrounding rocks; in particular, the bedding has a more significant impact on the stability of surrounding rocks $[3,4]$. At present, domestic and foreign experts believe that the deformation and failure of roadway surrounding rocks are closely related to the plastic zone, and the morphology and size of the plastic zone directly determine the failure form and degree of roadway surrounding rocks $[5,6]$. Therefore, it is of positive guiding significance to clarify the plastic zone distribution characteristics of surrounding rock in layered roadway for the study of surrounding rock deformation mechanism, support scheme design, roof accident treatment, and many other engineering practices $[7,8]$.

The research on the plastic zone of surrounding rock started from the mechanical analysis of circular roadway by domestic and foreign experts and scholars, of which abundant theoretical calculation results obtained during this period laid a solid foundation for the follow-up research. For example, through the method of mechanical analysis, people derived the famous formula of "Fenner-Kanerite" surrounding rock plastic zone of roadway $[9,10]$, and the influence laws of lateral pressure, intermediate principal stress, internal friction angle of surrounding rock, cohesion, and other factors on the distribution characteristics of surrounding rock plastic zone were clarified [11-14]. However, due to the limitation of theoretical calculation, it is impossible to make a direct research on the relationship between the plastic zone and deformation and failure of roadway surrounding rock. 
With the progress of science and technology, the visualization numerical simulation software can be used to conduct in-depth research on the plastic zone of roadway surrounding rock, and the research results can be combined with the actual engineering situation to some extent.

The homogenate of the plastic zone of surrounding rock of roadway has been studied systematically by the numerical simulation method [15-23]. In the course of these studies, the plastic zone morphology of surrounding rock with different section shapes, the general process of "plastic point $\longrightarrow$ plastic ring $\longrightarrow$ local distortion $\longrightarrow$ non-uniform expansion $\longrightarrow$ malignant expansion" of the plastic zone development, and the influence characteristics of temperature on the plastic zone of surrounding rock are obtained. According to the research results of this period, the mechanism of surrounding rock caving and rock burst in the roadway based on the plastic zone were established, which laid a solid theoretical foundation for the study on the stability control technology of surrounding rock in this type of roadway.

At present, the study of the plastic zone of the surrounding rock mainly focuses on three aspects: (1) theoretical calculation method of the radius of the plastic zone; (2) the influence of cohesion, internal friction angle, section shape, span, excavation, temperature, and other factors on the plastic zone; and (3) the relationship between the shape of the plastic zone and the deformation of the surrounding rock. However, there are relatively few studies on the distribution of plastic zones in layered roadways. Therefore, the influence of the lateral pressure coefficient, the shear strength of the bedding surface, and the tensile strength on the plastic zone of the surrounding rock of the layered roadway was studied in this paper. In addition, the distribution law and deformation characteristics of the plastic zone of the surrounding rock of layered roadways under different inclination angles are analyzed.

\subsection{Theoretical Analysis of the Failure of Layered Surrounding} Rock. The surrounding rock of layered roadway has many vertical or horizontal bedding planes, showing obvious anisotropy and heterogeneity. In this case, there is a single bedding surface, a single group of bedding surfaces, and multiple groups of bedding surfaces, as shown in Figure 1.

Figure 2 shows the mechanical model when a rock mass is cut by a single bedding plane $\mathrm{AB}$. In such case, there are two situations that can cause rock mass destruction: one is that the rock part is damaged by tension or compression shear, and the other is the failure of the bedding surface under tension or compression.

According to the structural plane mechanics model shown in Figure 2, the following formula can be obtained:

$$
\left.\begin{array}{c}
\sigma_{1}=\frac{1}{2}\left(\sigma_{1}+\sigma_{3}\right)+\frac{1}{2}\left(\sigma_{1}-\sigma_{3}\right) \cos 2 \beta \\
\tau=\frac{1}{2}\left(\sigma_{1}-\sigma_{3}\right) \sin 2 \beta
\end{array}\right\},
$$

where $\sigma$ and $\tau$ represent the normal stress and shear stress on the structural surface, respectively. $\sigma_{1}$ and $\sigma_{3}$ indicate the

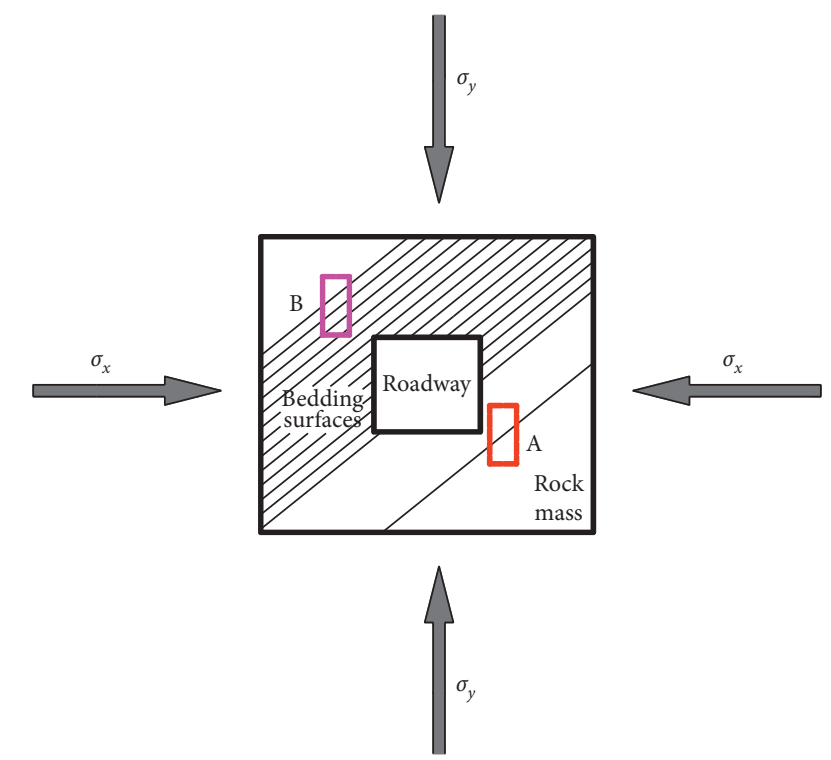

FIGURE 1: Composition of stratiform surrounding rock. "A" repeats a single structure plane. " $\mathrm{B}$ " indicates a single group of structure planes.

maximum and minimum principal stress, respectively. $\beta$ signifies the angle between the bedding surface and the maximum principal stress direction.

The strength curve of the structural surface obeys the Coulomb criterion, and the shear stress of the structural surface can be expressed as

$$
\tau=C_{j}+\sigma \tan b_{j}
$$

where $C_{j}$ and $b_{j}$ represent the cohesion and internal friction angle of the structural surface, respectively.

Equation (3) can be obtained according to equations (1) and (2).

$$
\sigma_{1}=\sigma_{3}+\frac{2\left(C_{j}+\sigma_{3} \tan b_{j}\right)}{\left(1-\tan b_{j} \cot \beta\right) \sin 2 \beta} .
$$

The angle between the bedding surface and the maximum principal stress direction can be summarized as

$$
\beta=\frac{\pi}{4}+\frac{b_{j}}{2},
$$

When the principal stress of a certain point in the rock satisfies formula (1), it means that the point in the rock is in a state of limit equilibrium. When the principal stress on the bedding plane $\mathrm{AB}$ satisfies formula (2), it indicates that the principal stress on the bedding plane $\mathrm{AB}$ is in a state of limit equilibrium. It can be seen from formula (3) that when the bedding surface enters the plastic state, $\sigma_{1}=f(\beta)$. Therefore, the strength of the surrounding rock mass is not a constant but changes with the inclination of the bedding surface.

When $\beta=90^{\circ}$ or $\beta=b_{j}$ and $\sigma_{1} \longrightarrow \infty$, it means that the rock is impossible to break along the bedding plane at this moment. However, it is also impossible for $\sigma_{1}$ to tend to infinity. Under this condition, it will be destroyed along a 


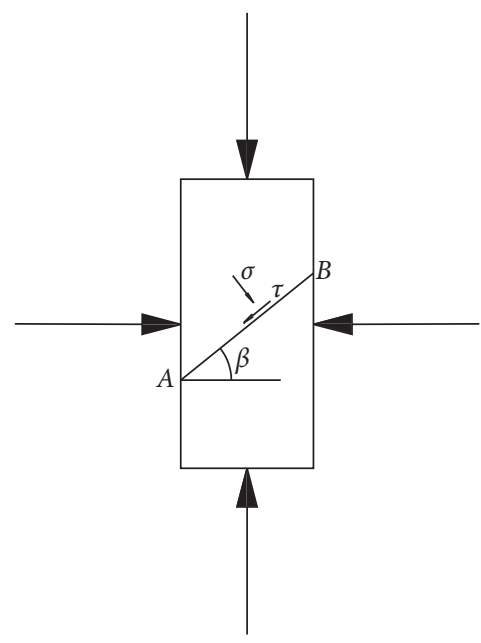

(a)

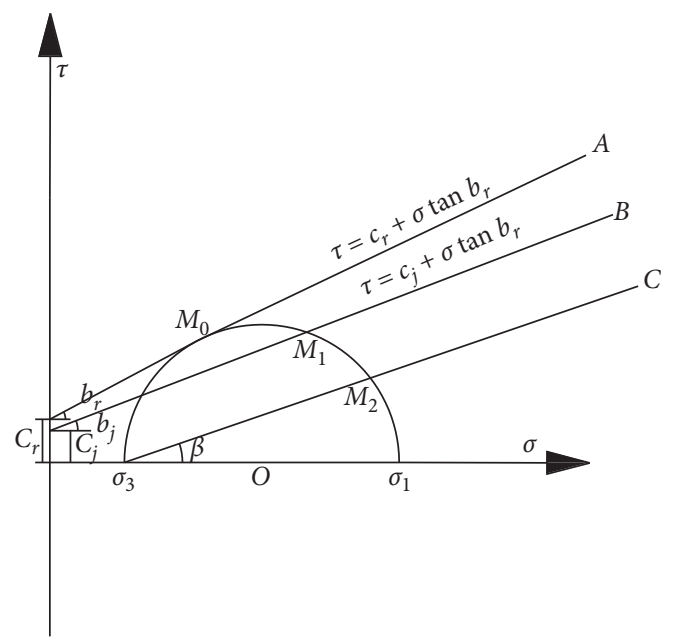

(b)

FIGURE 2: Mechanical analysis of rock with bedding plane.

certain bedding plane in the rock. Then the strength of the rock is the strength of the rock mass.

From the perspective of Mohr's circle (Figure 2(b)), line $A$ is the strength envelope of the rock, line B is the strength envelope of the bedding plane, and $M_{2}$ represents the stress state of a certain structural plane. If the stress state of a certain section of the rock is exactly at the position where line A and the Mohr circle are tangent (point $M_{0}$ ), then the rock will enter plastic failure along the section; otherwise, it will not enter the plastic failure state. The point $M_{1}$ is exactly on the strength envelope of the bedding plane, which means that the rock mass will enter a shear plastic state along the bedding plane. The point $M_{2}$ is below the strength envelope $\mathrm{B}$ of the bedding plane, which means that the rock mass will not enter a shear plastic state along the bedding plane. It can be seen that the failure condition of the bedding surface is that the strength limit curve of the bedding surface intersects the Mohr circle, which is obviously different from the failure situation, where the Mohr circle and the strength limit curve are tangent to the general homogeneous body.

According to equation (3), the uniaxial or triaxial compressive strength of the rock mass is controlled by the angle between the loading direction and the bedding plane. If there is a group of bedding planes with the same properties in the same kind of rock, when the maximum principal stress is perpendicular to the bedding plane, the strength of the rock mass has nothing to do with the bedding plane. At this time, the rock mass strength is the rock strength. When $\beta$ satisfies formula (4), the rock mass will be destroyed along the bedding plane, and the strength of the rock mass at this time is the strength of the bedding plane. When the maximum principal stress is parallel to the bedding plane, the rock mass will be destroyed due to the lateral expansion of the bedding plane. At this time, the strength of the rock mass will be between the above two conditions.

It can be seen from the above analysis that the size of the inclination of the bedding plane has a significant impact on the state (shear or tension) of the surrounding rock of the roadway. The size and shape of the plastic zone of the surrounding rock determine the failure mode and degree of the surrounding rock of the roadway.

\section{Numerical Simulation of Deformation and Failure Mechanism of Layered Roadway Surrounding Rock}

2.1. Model and Parameters. NURBS was used to build 7 models: a homogeneous body and six structural planes with different inclination angles $\left(0^{\circ}, 15^{\circ}, 30^{\circ}, 45^{\circ}, 60^{\circ}\right.$, and $90^{\circ}$ ). The dimensions of these models are length $\times$ width $\times$ height $=30 \times 30 \times 5 \mathrm{~m}$. The dimensions of the roadway section are length $\times$ width $=4 \times 3 \mathrm{~m}$. The number of grid divisions is between 45,000 and 60,000 . The number of layers is between 30 and 35.336 monitoring points were arranged at equal intervals $(1 \mathrm{~m})$ in the horizontal and vertical directions along the center of each roadway section. The upper boundary of the model is a stress boundary, and the remaining boundaries are displacement boundaries. Set the simulation depth to $600 \mathrm{~m}$ and the lateral pressure coefficient to 0.3 . The interface command in the FLAC3D program was used to establish the structural plane, as shown in Figure 3.

Because the number of mining roadways occupies the absolute advantage of all roadways and the mining roadways are mostly coal roadways, the mechanical parameters of coal seam No. 5 and the mechanical parameters of the original closed structural surface of coal seam No. 5 were assigned to the rock and structural surface characteristics in the model, respectively. The two parts of mechanical parameters come from the laboratory of the Institute of Coal Science and Technology, the Engineering Quality Inspection Center of the Yangtze River Scientific Research Institute of the Ministry of Water Resources, and the mechanical parameters of adjacent mines are given in Table 1. 


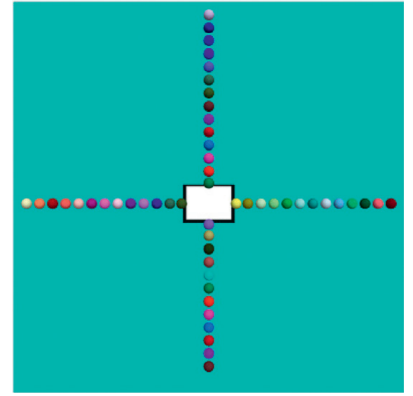

(a)

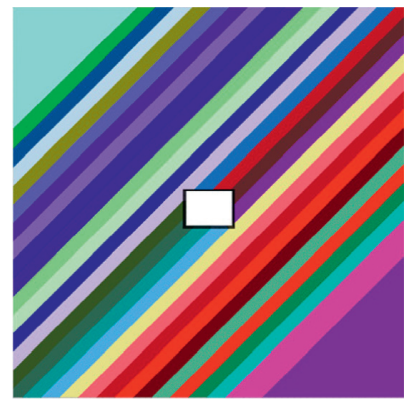

(e)

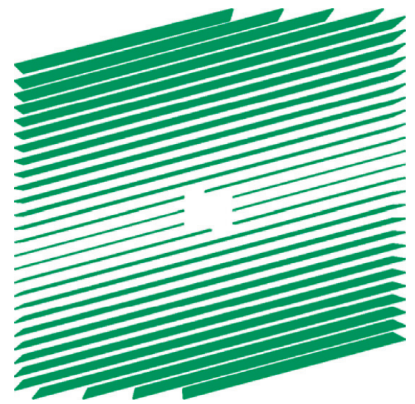

(i)

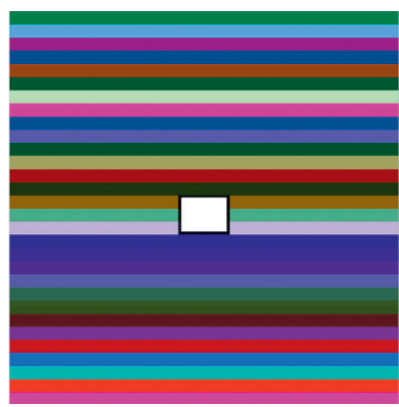

(b)

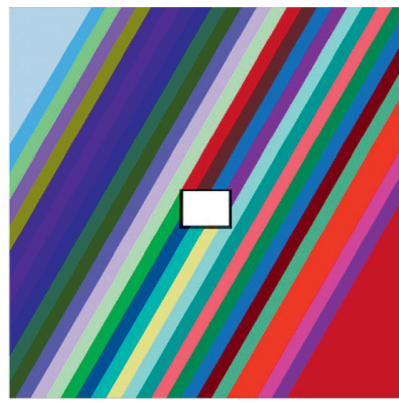

(f)

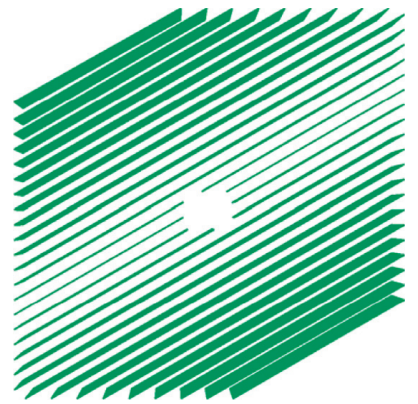

(j)

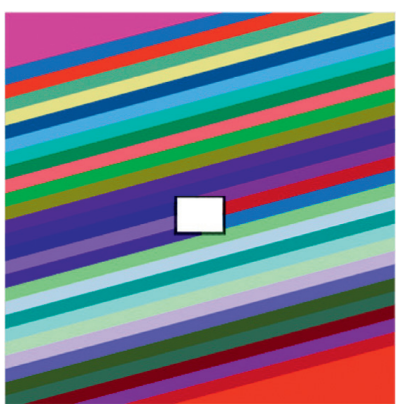

(c)

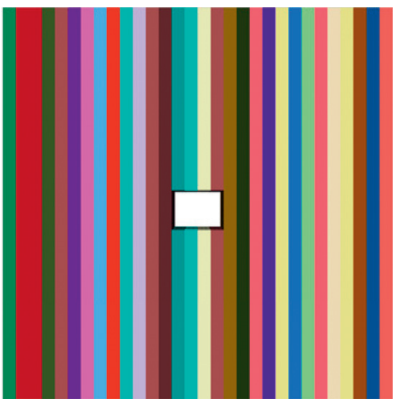

(g)

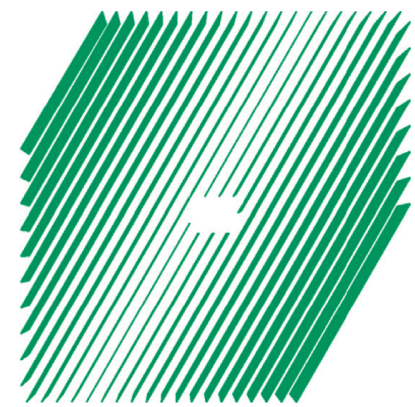

(k)

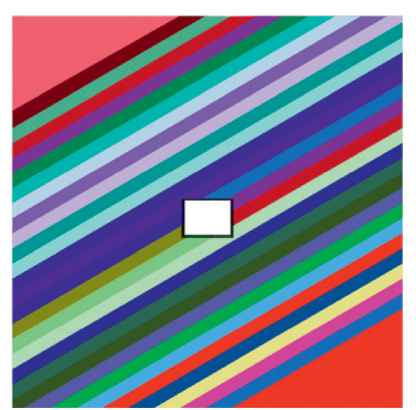

(d)

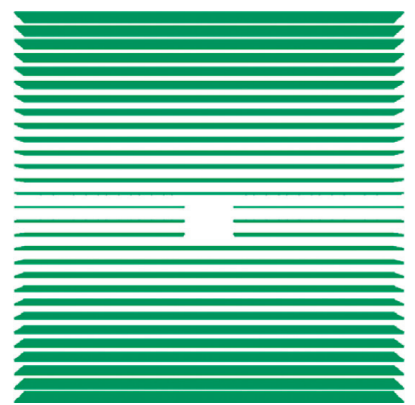

(h)

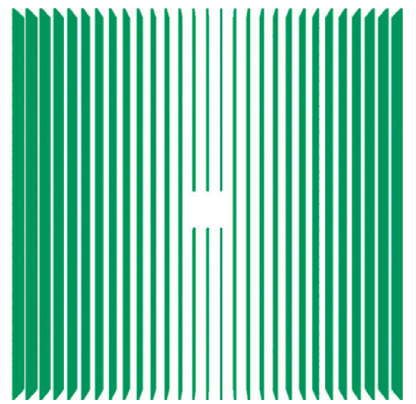

(l)

Figure 3: Models and their interfaces. (a) No structural plane. (b) Horizontal model. (c) Model with $15^{\circ}$. (d) Model with $30^{\circ}$. (e) Model with $45^{\circ}$. (f) Model with $60^{\circ}$. (g) Model with $90^{\circ}$. (h) Horizontal structural plane. (i) Structural plane with $15^{\circ}$. (j) Structural plane with $30^{\circ}$. (k) Structural plane with $45^{\circ}$. (l) Structural plane with $90^{\circ}$.

TABLE 1: Mechanical parameter of models.

\begin{tabular}{|c|c|c|c|c|c|c|}
\hline Group & $\begin{array}{c}\text { Internal friction } \\
\text { angle }\left({ }^{\circ}\right)\end{array}$ & $\begin{array}{c}\text { Cohesion } \\
\text { (MPa) }\end{array}$ & $\begin{array}{l}\text { Normal stiffness } \\
\left(\mathrm{MPa} \cdot \mathrm{cm}^{-1}\right)\end{array}$ & $\begin{array}{c}\text { Tangential stiffness } \\
\left(\mathrm{MPa} \cdot \mathrm{cm}^{-1}\right)\end{array}$ & $\begin{array}{c}\text { Density } \\
\left(\mathrm{kg} \cdot \mathrm{m}^{-3}\right)\end{array}$ & $\mathrm{UCS}(\mathrm{MPa})$ \\
\hline Rock & 45 & 3.12 & - & - & 1500 & 12.5 \\
\hline $\begin{array}{l}\text { Structural } \\
\text { plane }\end{array}$ & 31 & 1.16 & 160 & 45 & - & - \\
\hline
\end{tabular}

2.2. Roadway Surrounding Rock Stress. According to the failure criteria and the above analysis, the shear and tensile failure of the surrounding rock mass of the roadway are closely related to the principal stress and shear stress. Therefore, to clarify the generation mechanism and distribution characteristics of the plastic zone, it is necessary to clarify the distribution law of maximum shear stress and maximum principal stress. According to the knowledge of rock and soil mechanics, the maximum shear stress affects the shear failure of the surrounding rock, and the maximum principal stress can determine whether there is tensile stress in the surrounding rock (the smaller the value is, the easier it is to produce tensile stress). Because the tensile strength of the surrounding rock mass of the roadway is generally much lower than the compressive strength, it is very important to grasp the maximum principal stress of the surrounding rock mass of the roadway. It is worth noting that the requirements for numerical symbols in the software are opposite to the actual ones, so the minimum principal stress analysis of the software calculation results should be used in the analysis.

2.2.1. Maximum Shear Stress. Analyzing the calculation results of the seven models, it can be seen that the low stress 
part of the maximum shear stress (less than $2 \mathrm{MPa}$ ) is closely distributed in a certain area above and below the roof and floor of the roadway, and the closer to the edge of the roof and floor, the lower the stress value. The value of this range is difficult to make the rock enter the state of the plastic zone, so the maximum shear stress of the two sides should be analyzed.

From Figure 4(a), in the case of no structural surface, the high stress part (above $6.5 \mathrm{MPa}$ ) of the maximum shear stress is distributed in a butterfly shape vertically and symmetrically on both sides of the roadway. The 8.5-9 MPa part is distributed about $3 \mathrm{~m}$ from the two sides of the roadway. The "butterfly leaf" part reaches the farthest 15 meters from the top corner of the roadway.

Figure 4(b) shows that, in the case of horizontal stratification, the overall stress value distribution interval changes a little. The butterfly shape of the maximum shear stress and the edges of different stress values appear sharpened. The "butterfly body" part of the low-stress area of the roof and floor of the roadway is broken into two parts, and the lower part close to the floor is disordered.

Figure 4(c) shows that the butterfly shape of the maximum shear stress and the edge sharpening undulations of different stress values are more obvious. Moreover, there are high stress concentration areas of about $8 \mathrm{MPa}$ at the two bottom corners of the roadway. Since the angle between the maximum principal stress and the structural plane is $60^{\circ}$, which satisfies $\beta=(\pi / 4)+\left(b_{j} / 2\right)=60.5^{\circ}$, when the inclination angle of the structural plane is $30^{\circ}$, Figure $4(\mathrm{~d})$ shows that the butterfly shape of maximum shear stress sharpens serious water splash. A high stress concentration zone of 7$8 \mathrm{MPa}$ appears in the four corners of the roadway. Figure 4(e) shows that the high stress interval of the maximum shear stress is smaller than that of Figure 4(a), and the edges of the stress values in the upper left and lower right parts are sharpened. There are 6-7 MPa high stress concentration areas at the two corners of the roadway roof. Figure 4(f) shows that the butterfly shape of the maximum shear stress has changed significantly. The "butterfly leaf" on the lower left is missing a high-stress area, and the stress values in the upper left and lower right parts of the highstress area have sharp edges. There are 6-7 MPa high-stress concentration areas in the lower left and upper right corners of the roadway. Figure $4(\mathrm{~g})$ shows that the butterfly shape of the maximum shear stress and the edges of different stress values are also sharpened. However, the most notable feature is that the high-stress "butterfly leaf" part has a longer and narrower oblique direction and is obviously symmetrically distributed on both sides of the roadway.

2.2.2. Minimum Principal Stress. From the simulation results, the high stress part of the minimum principal stress (greater than $18 \mathrm{MPa}$ ) is distributed symmetrically in a fan shape at a distance of $2 \mathrm{~m}$ away from the two sides of the roadway, and the closer to the fan shaft, the higher the stress value. It is difficult for the value in this area to have tensile stress to make the rock enter a tensile plastic state. Therefore, the minimum value of the minimum principal stress of the roof and floor should be mainly analyzed.
It can be seen from Figure 5(a) that the low-stress part of the minimum principal stress is approximately triangular and symmetrically distributes within $7 \mathrm{~m}$ of the roof and floor. The stress within $1.2 \mathrm{~m}$ of the roof is below $3 \mathrm{MPa}$, and the farther away from the roof, the lower the stress value. Figure 5(b) shows that there is an obvious ladder phenomenon between the layers, which may be due to the delamination in the low-stress part. The stress is below $3 \mathrm{MPa}$ in the $2.2 \mathrm{~m}$ range. Figure 5(c) displays that the lowstress area below $3 \mathrm{MPa}$ is distributed at the upper right corner of the roof and the lower left corner of the floor with a local tip $(1 \mathrm{~m})$. The stress within $2.5 \mathrm{~m}$ is $6 \mathrm{MPa}$. Figure $5(\mathrm{~d})$ shows that the high-stress parts of the two sides have higher dispersion. The phenomenon of water splashing between layers is more prominent. The low-stress area (within $5 \mathrm{MPa}$ ) is concentrated within $1.5 \mathrm{~m}$ of the delamination tip.

Figure 5(e) shows that the high-stress parts of the two sides are further reduced and staggered up and down along the inclined layer. The low-stress area (within $5 \mathrm{MPa}$ ) of the roof and floor is located in the middle of the roof and floor in the form of a single peak. A small area of low stress appears in the middle of the left side and the bottom of the right side along the delamination tip. Figure 5(f) shows that the shape of the minimum principal stress has changed significantly, and the high-stress regions of both sides are sharply reduced. The low-stress area (within $5 \mathrm{MPa}$ ) is mainly distributed within $2 \mathrm{~m}$ of the roof, and the delamination tip of the left shoulder corner is within $1.5 \mathrm{~m}$ of the floor. Figure $5(\mathrm{~g})$ shows that the high-stress part of the two sides is almost consistent with the case without structure plane. However, the stress value is more intensive. A narrow and long lowstress distribution area with the same width as the roadway appears on the roof and floor, and the low-stress area within $2 \mathrm{MPa}$ is about $1.5 \mathrm{~m}$.

The maximum shear stress and minimum principal stress are closely related to the plastic zone of the surrounding rock of the roadway. The damage form and scale of the surrounding rock of the roadway are directly determined by the plastic zone. Therefore, to grasp the deformation and failure mechanism of the surrounding rock of a layered roadway, it is necessary to analyze the relationship between the plastic zone and the deformation of the surrounding rock.

\subsection{Plastic Zone of Surrounding Rock of Layered Roadway.} The distribution characteristics of the plastic zone of the surrounding rock under different conditions are shown in Figure 6 . The causes and distribution characteristics of the plastic zone shape of each model are analyzed here.

Figure 6(b) shows that the boundary line is in the form of a butterfly, and the boundary line matches well with the maximum shear stress of $7 \mathrm{MPa}$ and the minimum principal stress of 1.2 MPa. The two sides of the roadway are mostly shear failure due to the high-stress part of the shear stress. Figure 6(c) shows that the boundary line shape, shear failure area, and tension failure area are consistent with Figure 6(b). The reason is that the maximum principal stress is exactly perpendicular to the structural plane at this time, and the 
Zone maximum shear stress

Calculated by: volumetric averagin

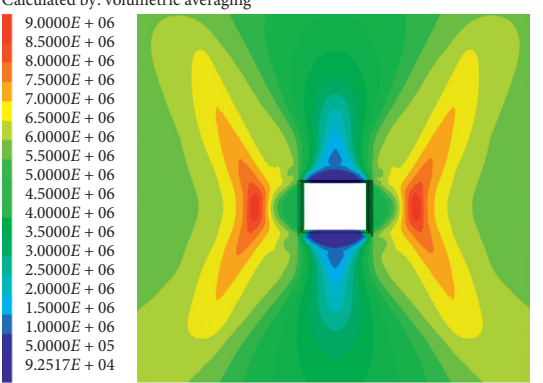

(a)

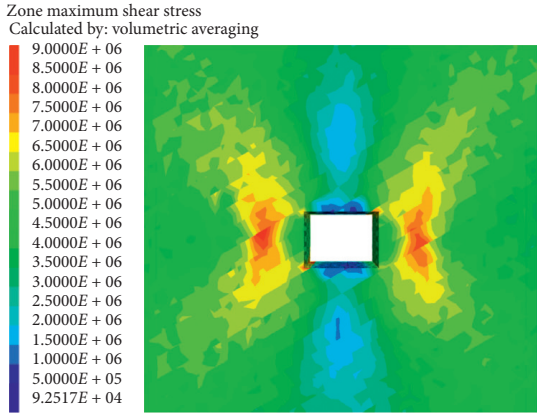

(d)
Zone maximum shear stress

Calculated by: volumetric averagin

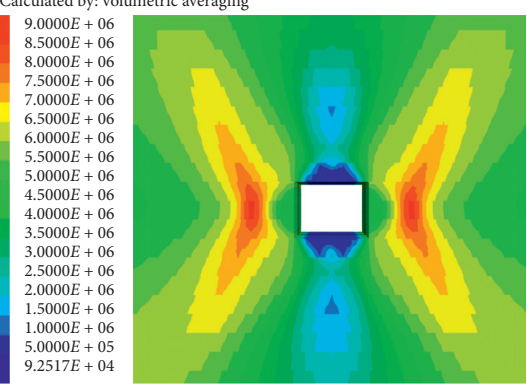

(b)

Zone maximum shear stress
Calculated by: volumetric averaging

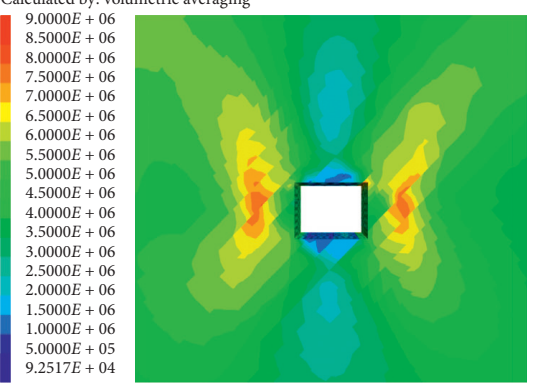

(e)

Zone maximum shear stress
Calculated by: volumetric averaging

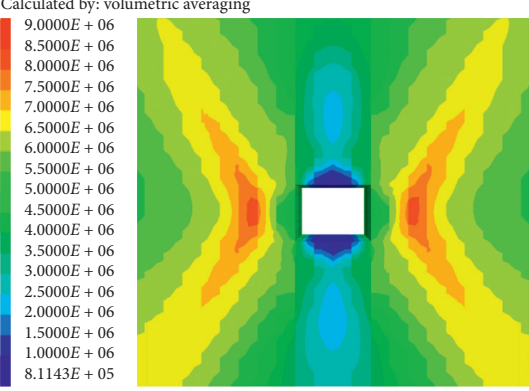

(g)
Zone maximum shear stress

Calculated by: volumetric averaging

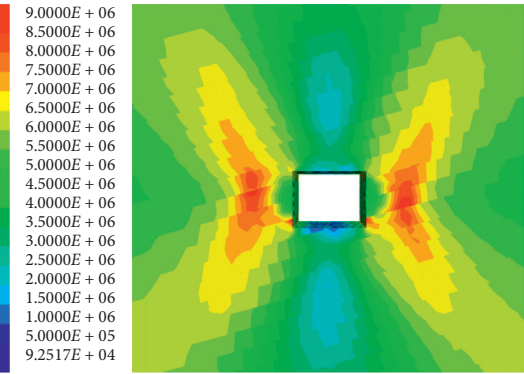

(c)

Zone maximum shear stress
Calculated by: volumetric averaging

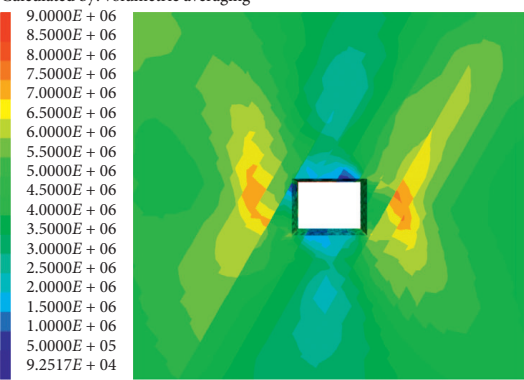

(f)

Figure 4: Distribution cloud diagram of maximum shear stress. (a) No structural plane. (b) $0^{\circ}$. (c) $15^{\circ}$. (d) $30^{\circ}$. (e) $45^{\circ}$. (f) $60^{\circ}$. (g) $90^{\circ}$.

strength of the rock mass is the rock strength. Figure $6(\mathrm{~d})$ shows that the boundary line shape still maintains the butterfly shape, but the "butterfly leaf" becomes wider, and the maximum extent of the tension failure zone of the two sides reaches $3 \mathrm{~m}$. Figure $6(\mathrm{e})$ shows that the butterfly shape is still relatively clear, but the continuity area of the plastic zone is further reduced. The tensile failure distribution of each inclined sublayer has obvious dispersion, which is closely related to the splash phenomenon of the maximum shear stress. The essence is that the angle between the maximum principal stress and the structural plane just satisfies formula (4), which is the most unfavorable angle. The strength of the rock mass is equal to the strength of the structural plane at this time, so large-scale damage occurs along the structural plane. Figure 6(f) shows that the butterfly shape has become smaller and more incomplete; in particular, the tip of the lower right corner has disappeared. The area of the plastic zone along the parallel direction of the structural plane is obviously larger than that of the vertical structural plane. This is because the maximum shear stress range is further reduced and the stress above $7 \mathrm{MPa}$ in the lower right corner disappears. Figure 6(g) shows that the butterfly shape becomes smaller and severely incomplete; in particular, the lower left corner completely disappears. The main reason for this situation is that the $60^{\circ}$ inclination angle changes the maximum shear stress distribution obviously, and the stress in the lower right corner is reduced to a level below $5 \mathrm{MPa}$. Figure $6(\mathrm{~h})$ shows that the butterfly shape becomes larger and very clear. The "butterfly leaf" became narrower and longer and reached a maximum of $14 \mathrm{~m}$. The reason is that the maximum principal stress is parallel to the structural plane, and the plastic failure is more serious under the action of shear stress.

In short, the shear failure plastic zone on both sides of the roadway ledge changes with the change of the maximum shear stress. The boundary line is consistent with the shear stress value that reaches the critical shear failure strength. The tensile failure plastic zone of the roof and floor of the roadway changes with the change of the minimum principal stress, and its boundary line is consistent with the boundary line of the $2 \mathrm{MPa}$ shear stress value. 


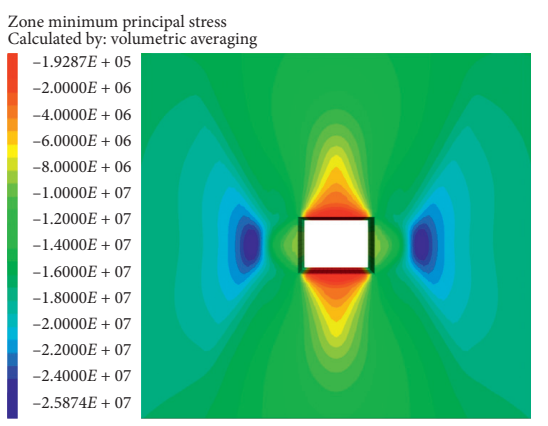

(a)

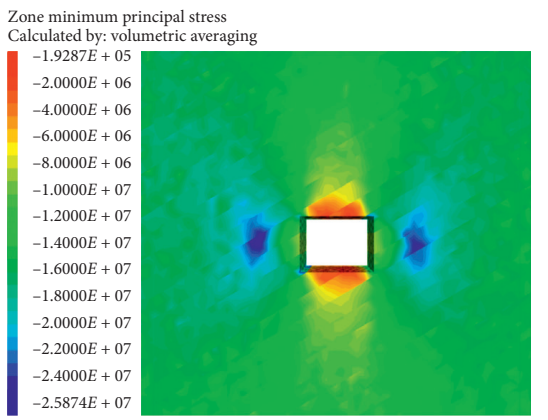

(d)

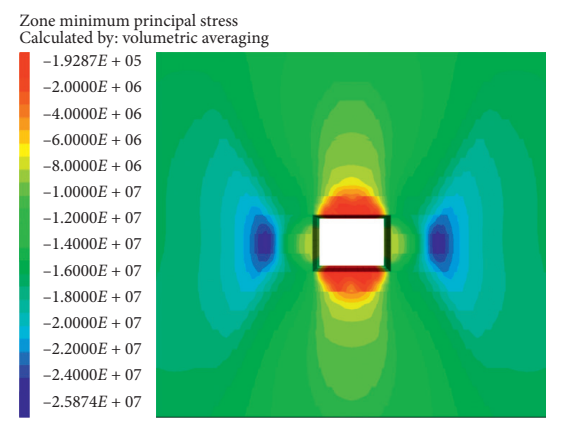

(b)

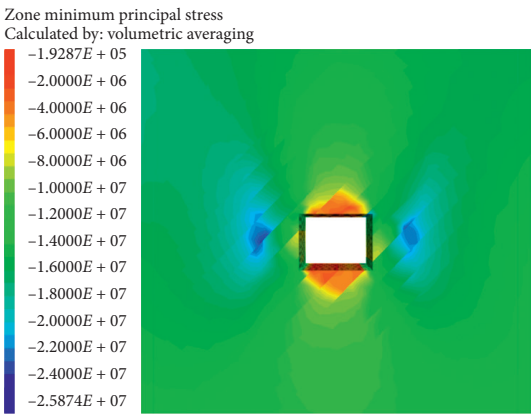

(e)

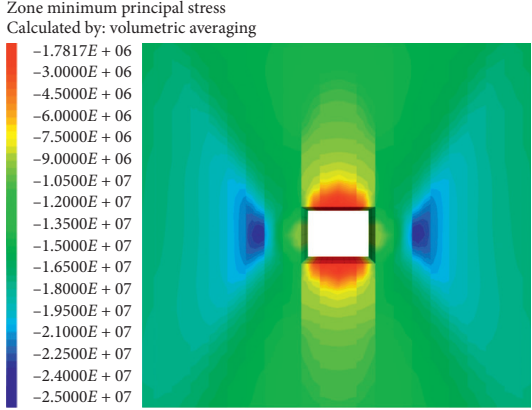

(g)

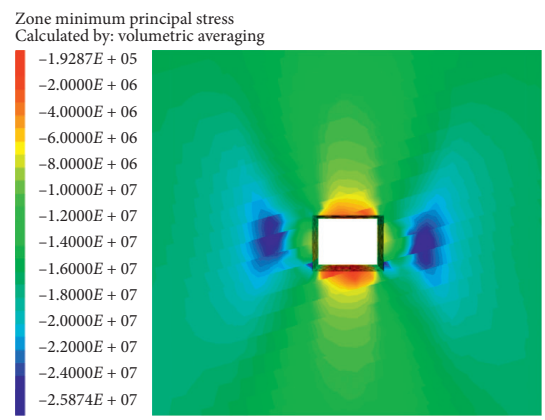

(c)

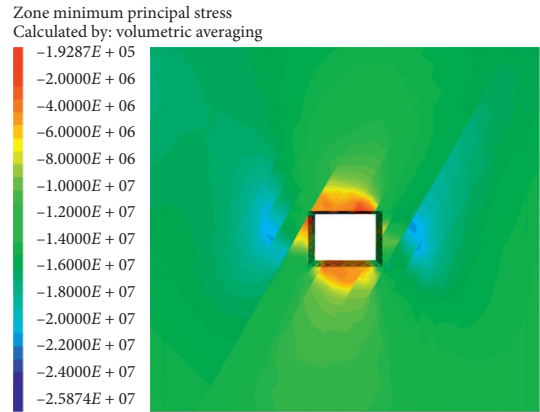

(f)

FIgURE 5: Distribution cloud diagram of minimum principal stress. (a) No structural plane. (b) $0^{\circ}$. (c) $15^{\circ}$. (d) $30^{\circ}$. (e) $45^{\circ}$. (f) $60^{\circ}$. (g) $90^{\circ}$.

2.4. Deformation and Failure of Surrounding Rock of Layered Roadway. The vertical and horizontal displacement cloud diagrams of the surrounding rock of the roadway are shown in Figures 7 and 8, respectively.

From Figures 7(b) and 7(c), in the two cases of unstructured surface and $0^{\circ}$ horizontal layering, the size and shape of the plastic zone are almost the same. However, the range of vertical displacement exceeding $9 \mathrm{~cm}$ is larger for the latter. Figures 6(b) and 7(c) also show a similar situation, which shows that when the shape and range of the plastic zone are the same, the more the surrounding rock is cut in layers, the larger the deformation is.

From Figures $6(\mathrm{c})-6(\mathrm{e})$ and $7(\mathrm{c})-7(\mathrm{e})$, the range of the continuous plastic zone ("butterfly" shape) gradually decreases with the increase of the inclination angle when the structural plane inclination angle is $0^{\circ} \sim 30^{\circ}$. Under the structural plane with $30^{\circ}$, a large range of discrete plastic zones appear in the figure. In addition, the high displacement area of the vertical displacement of the surrounding rock gradually decreases with the decrease of the plastic zone.
Figures $8(\mathrm{c})-8(\mathrm{e})$ show that, with the increase of the inclination angle, an inclined horizontal high displacement area appears in the upper left corner and the lower left corner of the surrounding rock of the roadway, while the horizontal high displacement area at the upper right and lower right corners decreases. However, when the structural plane inclination is $30^{\circ}$, the large-scale discrete plastic zone does not cause large-scale damage to the surrounding rock, which indicates that the discrete plastic zone has little effect on the damage of the surrounding rock. Compared with the structural plane inclination angle of $30^{\circ}$, when the structural plane inclination angle is $45^{\circ}$, the tensile failure zone of the roof and floor is significantly increased by $1.0 \mathrm{~m}$.

Figures 6(f) and 7(f) show that the high-displacement zone of vertical displacement under this plastic zone increases significantly within the increasing range of the tensile plastic zone, while the remaining vertical displacement zones gradually decrease along the structural plane. Figures 5(f) and 7(f) show that the shear failure plastic zone missing in the lower right corner causes the high 


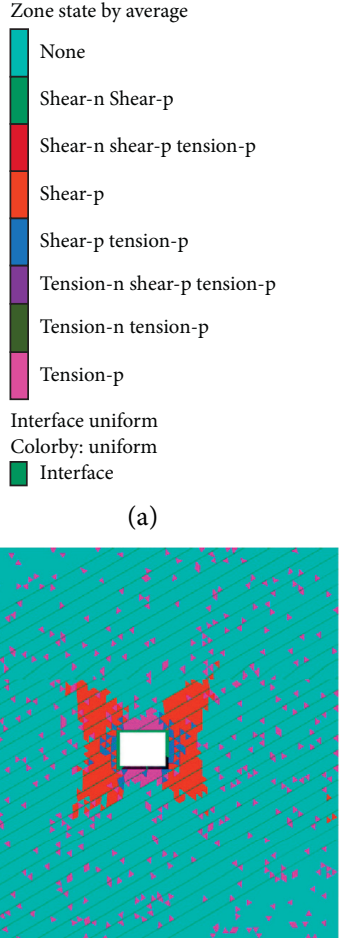

(e)

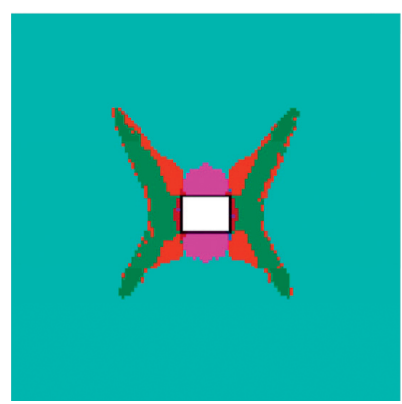

(b)

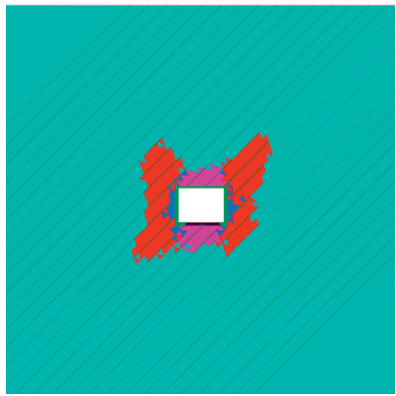

(f)
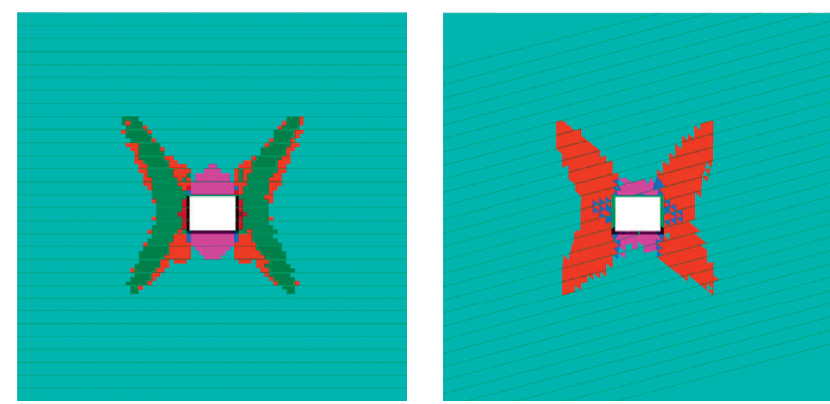

(c)

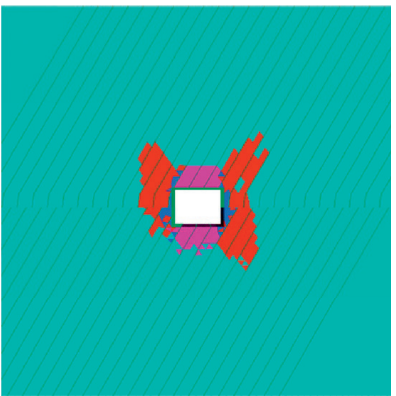

(g)

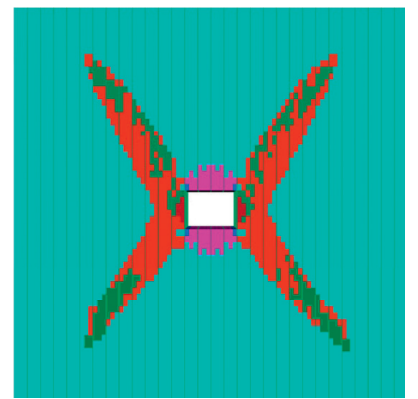

(h)

Figure 6: Plastic zone of seven models. (a) Plastic zone legend. (b) No structural plane. (c) Horizontal structural plane. (d) Structural plane with $15^{\circ}$. (e) Structural plane with $30^{\circ}$. (f) Structural plane with $45^{\circ}$. (g) Structural plane with $60^{\circ}$. (h) Vertical structural plane.

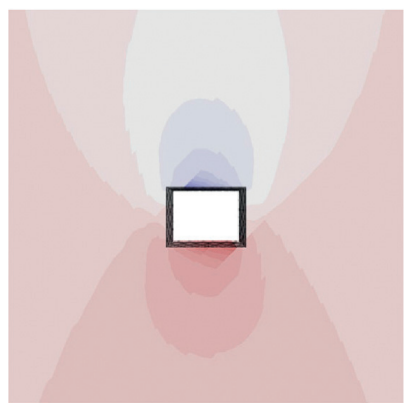

(f)

(b)

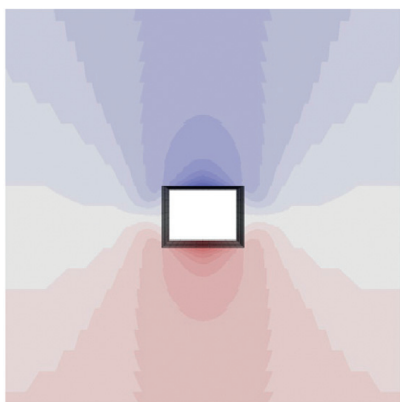

(c)

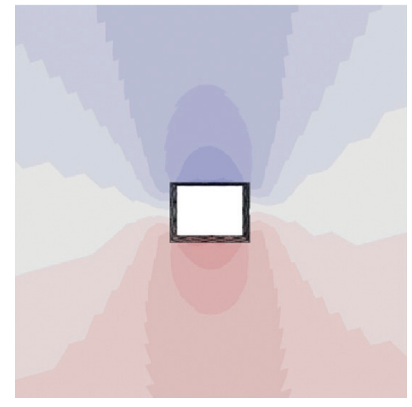

(d)

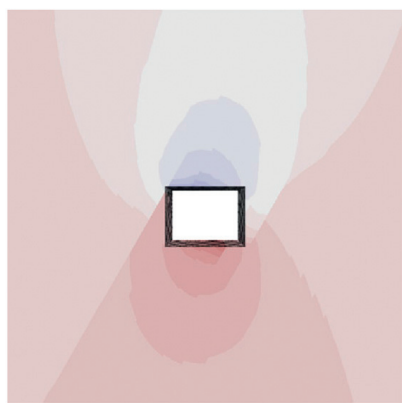

(g)

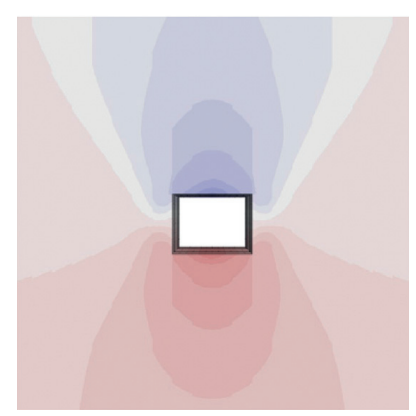

(h)

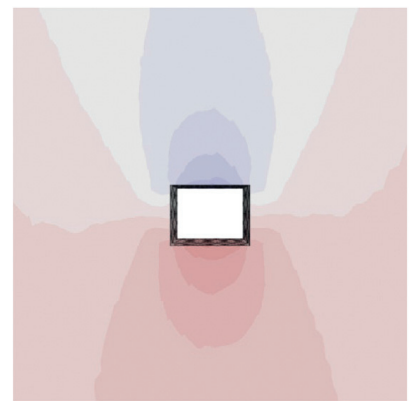

(e)

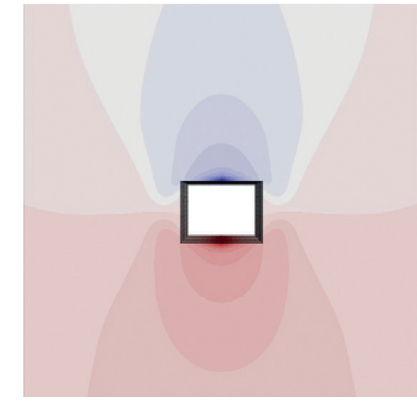

Figure 7: Vertical displacement nephogram. (a) Displacement legend. (b) No structural plane. (c) Horizontal structural plane. (d) Structural plane with $15^{\circ}$. (e) Structural plane with $30^{\circ}$. (f) Structural plane with $45^{\circ}$. (g) Structural plane with $60^{\circ}$. (h) Vertical structural plane. 


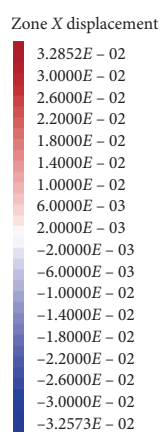

(a)

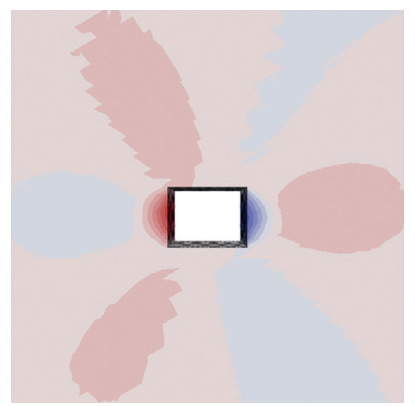

(e)

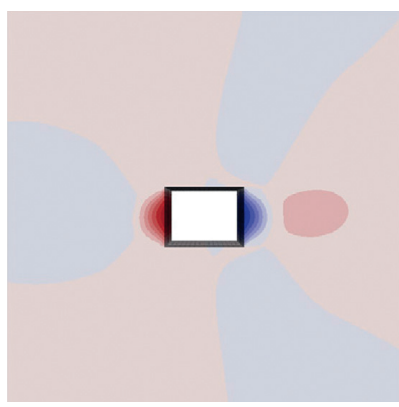

(b)

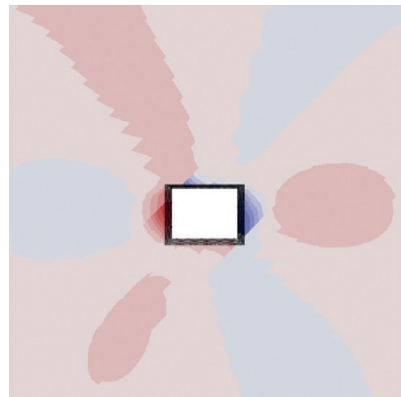

(f)

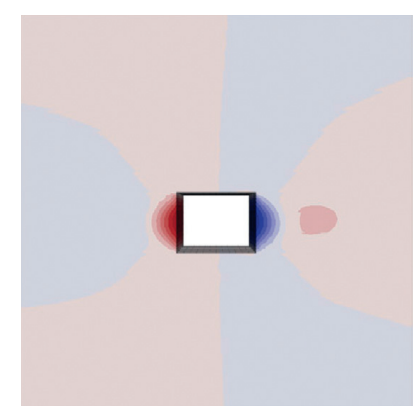

(c)

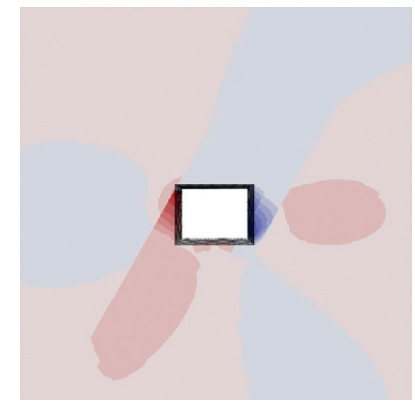

(g)

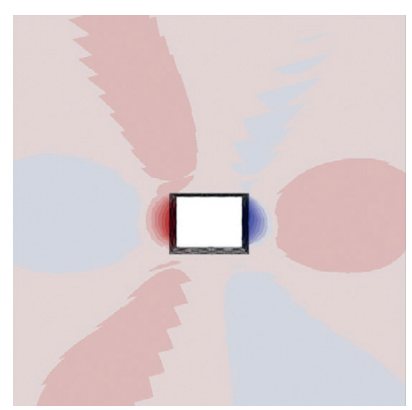

(d)

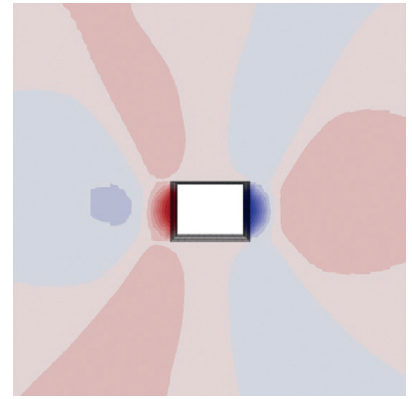

(h)

Figure 8: Horizontal displacement nephogram. (a) Displacement legend. (b) No structural plane. (c) Horizontal structural plane. (d) Structural plane with $15^{\circ}$. (e) Structural plane with $30^{\circ}$. (f) Structural plane with $45^{\circ}$. (g) Structural plane with $60^{\circ}$. (h) Vertical structural plane.

displacement zone of the horizontal displacement to be relatively reduced in this part. The irregularity of the plastic zone in the upper left corner aggravates the expansion of the high displacement zone in the upper left corner. Moreover, the high displacement zone is connected with the two high horizontal displacement zones.

Figures $6(\mathrm{~g})$ and $7(\mathrm{~g})$ show that the plastic zone of the surrounding rock of the roadway lacks the shear failure zone in the lower left corner when the structural plane dip is $60^{\circ}$, which makes this part extremely irregular, so that the vertical displacement at the left and lower left corners is larger than that at the corresponding right side. Figures $6(\mathrm{~g})$ and $8(\mathrm{~g})$ show that this situation also causes the horizontal displacement to form a high-level displacement zone in this area.

Figures $6(\mathrm{~h})$ and $7(\mathrm{~h})$ show that when the structural plane dip is $90^{\circ}$, the "butterfly" shape of the plastic zone of the surrounding rock becomes larger and the "butterfly leaf" becomes thinner and longer. In this case, the distribution range and size of the vertical displacement are between the unstructured surface and the horizontal structure surface. Figures $6(\mathrm{~h})$ and $8(\mathrm{~h})$ show three obvious changes in the high displacement area of horizontal displacement: (1) The range of high-level displacement above $3 \mathrm{~cm}$ within $3 \mathrm{~m}$ of the left and right sides increases significantly. (2) Compared with the case where the structural plane inclination angle is $15^{\circ} \sim 60^{\circ}$, the high-level displacement area $3 \mathrm{~m}$ away from the two sides is obviously larger. (3) The high-level displacement area with four inclination angles reappears in a butterfly shape and the range is increased.

\section{Distribution Characteristics of Plastic Zone of Surrounding Rock of Layered Roadway under Different Influencing Factors}

The plastic zone of surrounding rock can intuitively reflect the deformation and failure of surrounding rock. The main factors that affect the distribution characteristics of plastic zone of surrounding rock in layered roadway include stress environment, mechanical properties of rock mass, and bedding plane. In order to clarify the influence laws of different influence factors on the deformation and failure of surrounding rock, it is necessary to clarify the distribution characteristics of plastic zone of surrounding rock under different influence factors. Therefore, the dip angle model of $15^{\circ}$ bedding plane was taken as an example, and the single factor research method was adopted to carry out numerical simulation study one by one to analyze the deformation and failure characteristics of roadway surrounding rock under different influencing factors.

3.1. Lateral Pressure Coefficient. In order to clarify the influence of stress environment on the distribution characteristics of plastic zone in layered roadway surrounding rock, the lateral pressure coefficients $\lambda=0.3,0.6,1.0,1.5,2.0$, and 2.5 were set, respectively, for numerical simulation calculation. The calculation results are summarized as shown in Figure 9.

When $\lambda=0.3$, the plastic zone as a whole is symmetrically distributed around the roadway in the form of " $X$," and 

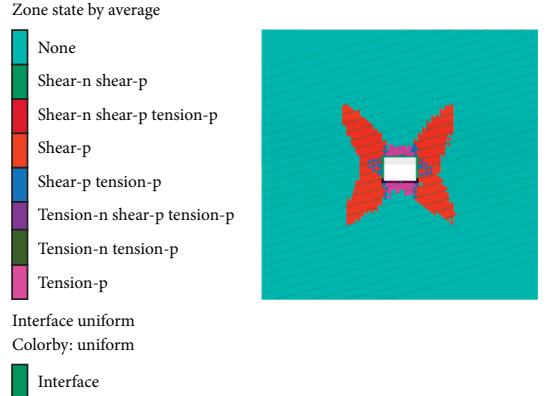

(a)

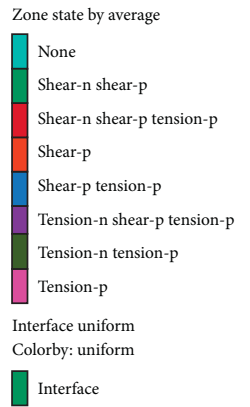

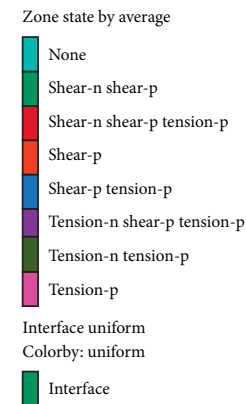

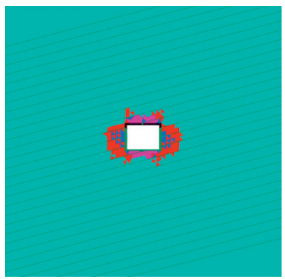

(b)

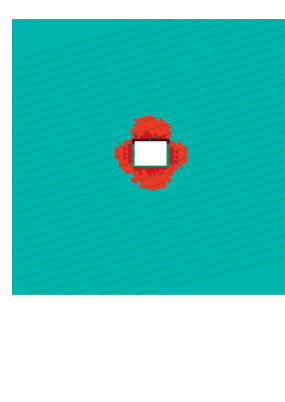

(d)

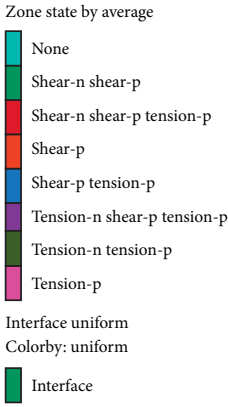

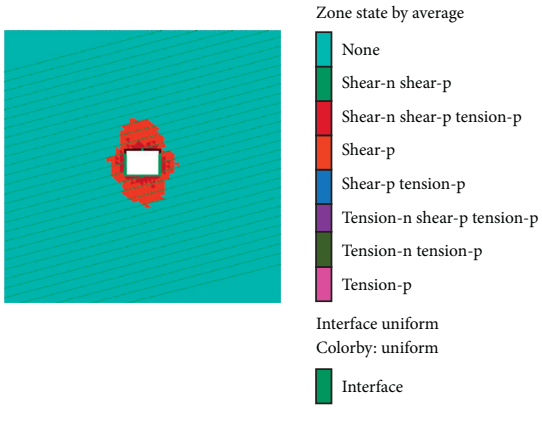
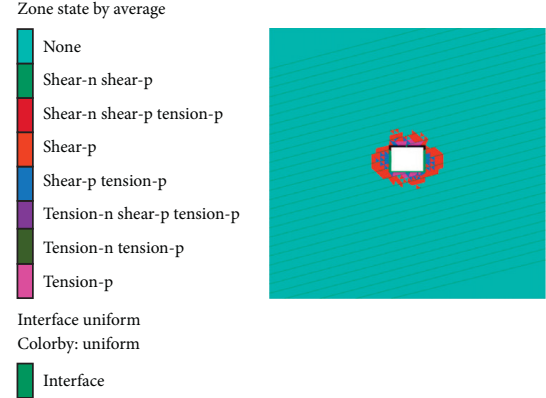

(c)

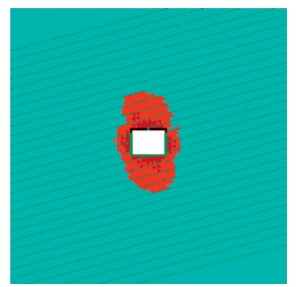

(f)

FiguRE 9: Distribution pattern of plastic zone under different lateral pressure coefficients. (a) $\lambda=0.3$. (b) $\lambda=0.6$. (c) $\lambda=1.0$. (d) $\lambda=1.5$. (e) $\lambda=2.0$. (f) $\lambda=2.5$.

the diagonals are, respectively, inclined upward and downward, which is mainly due to the great nonuniformity of horizontal stress and vertical stress. When $\lambda=0.6$, the overall range of the plastic zone decreases and the " $X$ " shaped tip degenerates, which is mainly because the tip of the plastic zone decreases obviously with the increase of horizontal stress. When $\lambda=1.0$, the shape of the plastic zone evolves into a regular ellipse, and the plastic zone area of roof and floor began to increase, indicating that the deformation and failure of roof and floor began to become serious with the increase of horizontal stress. When $\lambda=1.5$, the plastic zone morphology changes obviously, and the plastic zone area begins to expand significantly on the roof and floor, which is the result of the enhanced action of horizontal stress on the roof and floor. When $\lambda=2.0$ and 2.5, the plastic zone of roadway roof and floor expands greatly under the action of high horizontal stress, and the effect of vertical stress on the two sides is relatively weak. It can be seen that the change of lateral pressure coefficient directly changes the geometry of the plastic zone.

3.2. Cohesion and Internal Friction Angle of Rock Strata. In order to clarify the influence of mechanical properties of rock strata on the distribution characteristics of plastic zone of roadway surrounding rock, the internal friction angles of $43^{\circ}, 44^{\circ}, 46^{\circ}$, and $47^{\circ}$ and the cohesion forces of $2.81 \mathrm{MPa}$, $3.01 \mathrm{MPa}, 3.21 \mathrm{MPa}$, and $3.41 \mathrm{MPa}$ were, respectively, set for simulation calculation, and the plastic zones under various conditions were sorted out as shown in Figures 10 and 11.

It can be seen from Figure 10 that the cohesion of rock mass has a significant influence on the size of the plastic zone of surrounding rock, but it has no obvious influence on the distribution form of the plastic zone of surrounding rock. When the cohesion of rock mass increases from $2.81 \mathrm{MPa}$ to $3.41 \mathrm{MPa}$ with a gradient of $0.2 \mathrm{MPa}$, the plastic zone of surrounding rock remains unchanged and the range is gradually reduced, which indicates that the plastic zone can be controlled by increasing the cohesion of surrounding rock of roadway, but its shape cannot be changed.

As can be seen from Figure 11, the internal friction angle of rock stratum has a significant influence on the size of the plastic zone of surrounding rock but has no significant influence on the distribution of the plastic zone of surrounding rock. When the internal friction angle of rock stratum increases from $44^{\circ}$ to $46^{\circ}$ with a gradient of $1^{\circ}$, the plastic zone of surrounding rock remains unchanged and the range decreases gradually, which indicates that the plastic zone size can be controlled by increasing the internal friction angle of rock stratum, but the shape of the plastic zone cannot be changed.

\subsection{Internal Friction Angle and Cohesion of Bedding Surface.} In order to reveal the influence laws of friction angle and cohesion of bedding on the distribution of plastic zone of surrounding rock, four conditions of internal friction angle, $15^{\circ}, 31^{\circ}, 45^{\circ}$, and $60^{\circ}$, and four conditions of cohesion, $0.1 \mathrm{MPa}$, $0.6 \mathrm{MPa}, 1.1 \mathrm{MPa}$, and 1.6 MPa, were, respectively, set for simulation calculation. The plastic zones under various conditions are sorted out as shown in Figures 12 and 13.

Figure 12 shows that the plastic zone of surrounding rock is closely related to the internal friction angle of the bedding plane. When the internal friction angle of the bedding plane is $15^{\circ}$, the two sharp angles of the plastic zone show obvious 


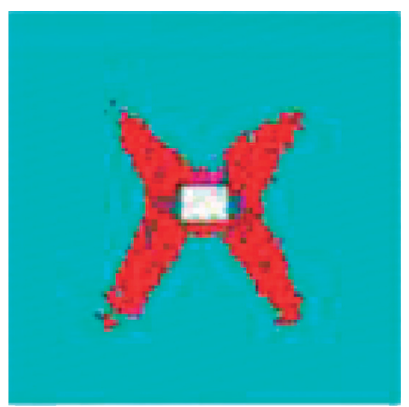

(a)

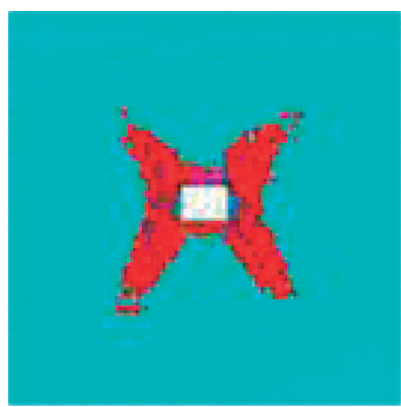

(b)

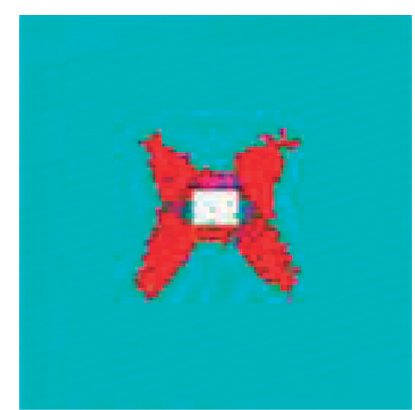

(c)

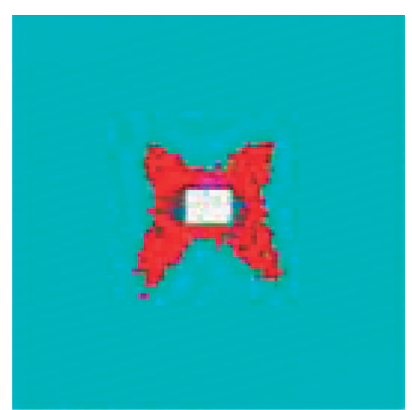

(d)

FIgURe 10: Morphology of plastic zone under different strata cohesion. (a) $2.81 \mathrm{MPa}$. (b) $3.01 \mathrm{MPa}$. (c) $3.21 \mathrm{MPa}$. (d) $3.41 \mathrm{MPa}$.

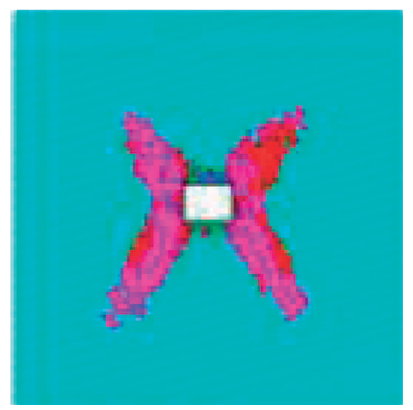

(a)

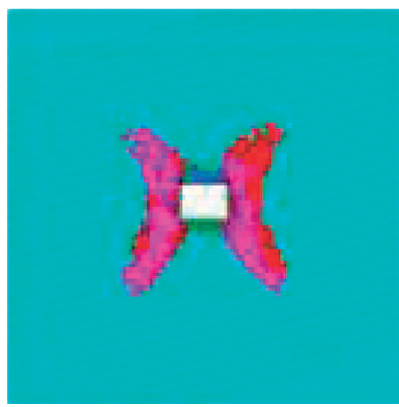

(b)

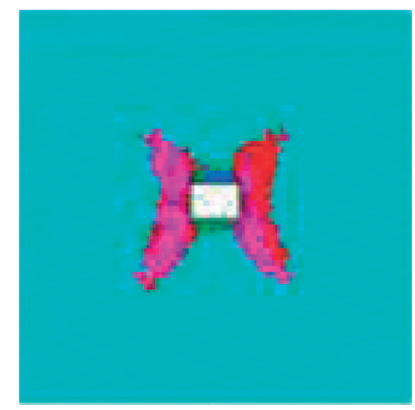

(c)

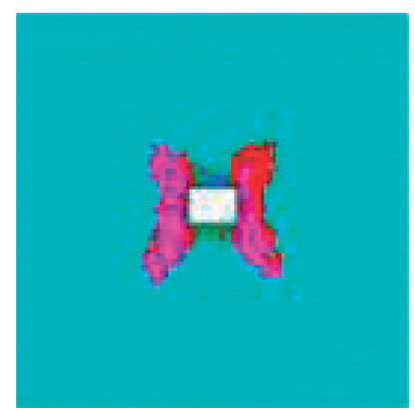

(d)

FIgURE 11: Morphology of plastic zone under different angle of internal friction of rock strata. (a) $43^{\circ}$. (b) $44^{\circ}$. (c) $46^{\circ}$. (d) $47^{\circ}$.

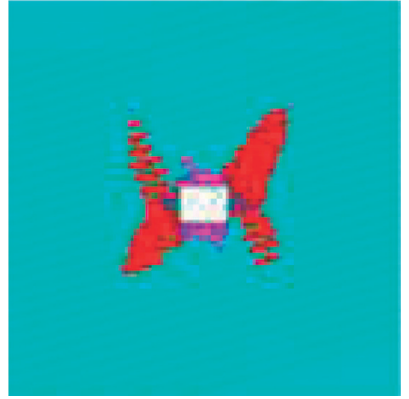

(a)

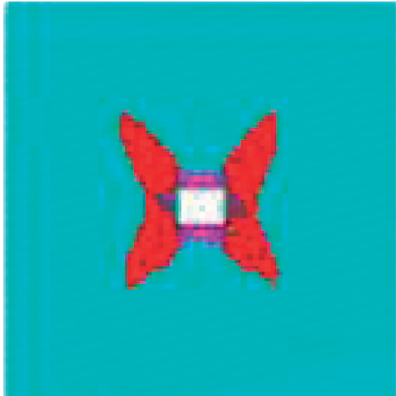

(b)

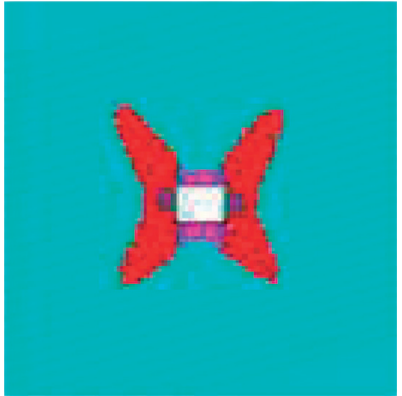

(c)

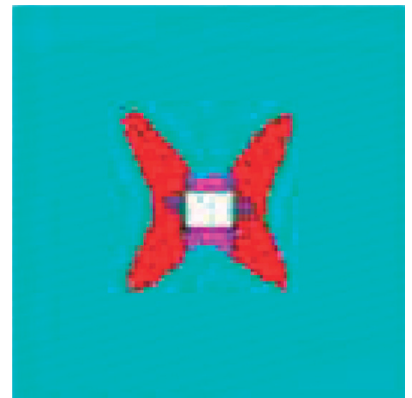

(d)

FIgURE 12: Morphology of plastic zone under different strata internal friction angle. (a) $15^{\circ}$. (b) $31^{\circ}$. (c) $45^{\circ}$. (d) $60^{\circ}$.

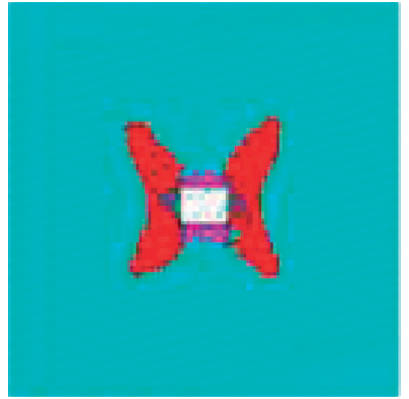

(a)

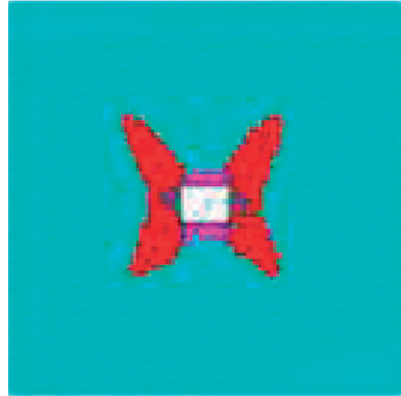

(b)

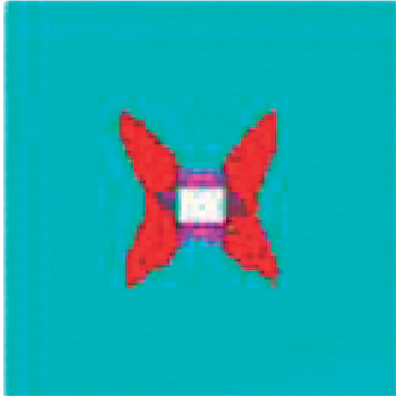

(c)

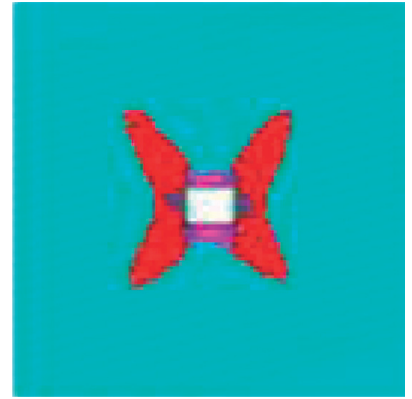

(d)

Figure 13: Morphology of plastic zone under different cohesion of rock strata. (a) $43^{\circ}$. (b) $44^{\circ}$. (c) $46^{\circ}$. (d) $47^{\circ}$. 
dispersion phenomenon. When the internal friction angle of bedding plane increases to $31^{\circ}$, the dispersion phenomenon of two sharp angles in the plastic zone disappears. As the internal friction angle continues to increase, the change in the shape and size of the plastic zone of surrounding rock of roadway is relatively small. This indicates that increasing the friction angle in the roadway bedding plane can reduce the phenomenon of overbedding development in the plastic zone, but it cannot change its shape and size.

Figure 13 shows that the plastic zone of surrounding rock presents a slight increase trend with the increase of the cohesion of bedding plane. The increase was relatively modest and no obvious change occurs when it increases to a certain extent. For example, when the cohesiveness of bedding plane is $0.1 \mathrm{MPa}$, the maximum boundary of plastic zone of surrounding rock is $6.21 \mathrm{~m}$; when the cohesiveness of bedding plane increases to $1.6 \mathrm{MPa}$, the maximum boundary of plastic zone of surrounding rock is $7.12 \mathrm{~m}$, which only increases by $1 \mathrm{~m}$. This phenomenon does not mean that increasing the cohesion of surrounding rock strata is increasing the deformation and failure of the roadway. On the contrary, increasing the cohesion of surrounding rock strata strengthens the homogeneity of surrounding rock of two layers and makes the plastic zone of surrounding rock of the roadway expand like in homogeneous body.

3.4. Normal Stiffness and Shear Stiffness of Bedding Surface. Normal stiffness and the tangential stiffness are the key mechanics properties of bedding surfaces, which have important influence on stability of rock mass. In order to show the influence of these two factors on the distribution of plastic zone of surrounding rock directly, four cases of normal stiffness, $5 e 9 \mathrm{MPa} \cdot \mathrm{cm}^{-1}, 10 e 9 \mathrm{MPa} \cdot \mathrm{cm}^{-1}, 15 e 9$ $\mathrm{MPa} \cdot \mathrm{cm}^{-1}$, and $20 e 9 \mathrm{MPa} \cdot \mathrm{cm}^{-1}$, and four cases of tangent stiffness, $0.5 e 9 \mathrm{MPa} \cdot \mathrm{cm}^{-1}, 2.5 e 9 \mathrm{MPa} \cdot \mathrm{cm}^{-1}, 4.5 e 9 \mathrm{MPa} \cdot \mathrm{cm}^{-1}$, and $6.5 e 9 \mathrm{MPa} \cdot \mathrm{cm}^{-1}$, were, respectively, set for simulation calculation.

As can be seen from Figure 14, when the normal stiffness of the plastic zone of surrounding rock of the roadway is $5 e 9 \mathrm{MPa} \cdot \mathrm{cm}^{-1}$, the upper and lower left butterflies reach $10.81 \mathrm{~m}$ and $7.81 \mathrm{~m}$, respectively, and their full development forms an asymmetrical distribution state with the right. When the normal stiffness is increased to $11 \mathrm{e} 9 \mathrm{MPa} \cdot \mathrm{cm}^{-1}$, the asymmetry decreases obviously. With the further reduction of the normal stiffness, the butterfly morphology gradually becomes symmetrical, and the reduction of the left plastic zone becomes smaller. When the normal stiffness is increased to $20 e 9 \mathrm{MPa} \cdot \mathrm{cm}^{-1}$, the plastic zone morphology changes a little. It shows that the too low normal stiffness of bedding plane can cause the asymmetric distribution of the plastic zone of surrounding rock.

Figure 15 shows the influence rule of tangential stiffness on the plastic zone of surrounding rock. When the tangential stiffness is $0.5 e 9 \mathrm{MPa} \cdot \mathrm{cm}^{-1}$, the plastic zone of surrounding rock of roadway has obvious bedding development phenomenon. When the tangential stiffness is $2.5 e 9 \mathrm{MPa} \cdot \mathrm{cm}^{-1}$, the distribution of the penetration in the plastic zone of surrounding rock disappears. With the further increase of tangential stiffness, the plastic zone of surrounding rock becomes symmetrical. When the tangential stiffness increases to a certain extent, the shape and size of the plastic zone do not change significantly.

\section{Field Verification}

4.1. Overview. The layout of track roadway of coal seam No. 15 is shown in Figure 16. The track roadway of coal seam No. 15 in Baoan coal mine of Shanxi Province is located in the south wing panel area, which is used to mine coal seam No. 15 . The design length of the roadway is $1348 \mathrm{~m}$, the north is $80 \mathrm{~m}$ away from the stop line, and the south is +315 horizontal roadway and return air roadway of coal seam No. 15 .

The roadway has an average inclination angle of $8^{\circ}$ and buried depth of $725 \mathrm{~m}$. The roadway is a rectangular section with a width of $4.0 \mathrm{~m}$ and a height of $3.8 \mathrm{~m}$. The immediate roof and main roof are $\mathrm{K}_{2}$ limestone with $2.85 \mathrm{~m}$ and sandy mudstone with $3.0 \mathrm{~m}$, respectively. The immediate floor and main roof are interband coal with $1.6 \mathrm{~m}$ and sandy mudstone with $3.57 \mathrm{~m}$. The bar graph of lithology of roadway surrounding rock is shown in Figure 17.

4.2. Deformation Characteristics of the Roadway. The surrounding rock deformation of the roadway is very serious due to the influence of high ground stress and structural surface. This lane is a typical multilayered roadway controlled by inclined structural planes. The deformation and failure characteristics of the roadway are as follows:

(1) Serious internal squeezing and deformation of the shoulders of the roadway roof. As shown in Figure 18(a), the shoulder corners of the roof are so severely squeezed that the original rectangular shape becomes an isosceles trapezoid shape. In addition, the failure of the bolt (cable) is prominent, and the roof sinks up to $1.5 \mathrm{~m}$. From Figure 18(b), the layered distribution of the roof is very obvious.

(2) The two corners of the roadway floor heave and deform seriously. The surrounding rock near the bottom corner of roadway floor heaves laterally, which makes the original regular right angle become a straight line. The floor heave is serious in the whole roadway, and the most serious floor heave section is $1.2 \mathrm{~m}$. The total deformation of roof and floor is more than $2.5 \mathrm{~m}$.

Borehole imager was used to observe the damage of surrounding rock. Five boreholes with $11 \mathrm{~m}$ in depth were arranged on the roof and the two sides of the roadway for observing the damage of surrounding rock. The borehole of the floor was not constructed due to the difficulty of construction and observation. The typical borehole fracture images of surrounding rock in different depths are shown in Figure 19.

In order to visually display the distribution of cracks in different parts of the surrounding rock, the distribution of fractures was redrawn according to Figure 19, and the result was shown in Figure 20. 


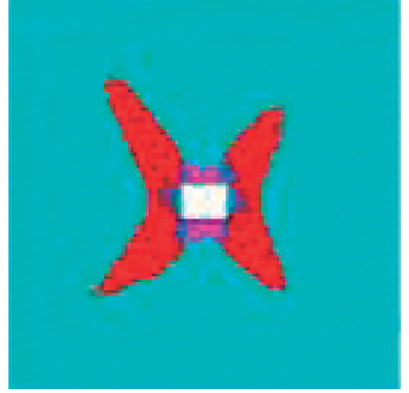

(a)

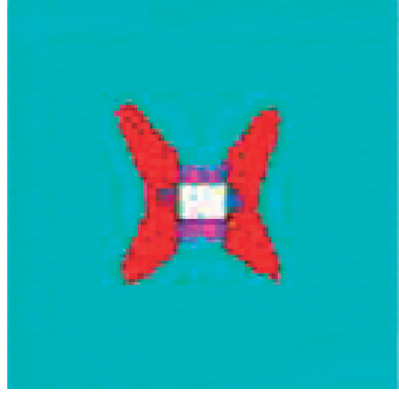

(b)

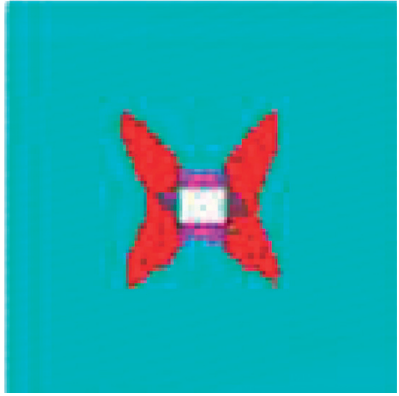

(c)

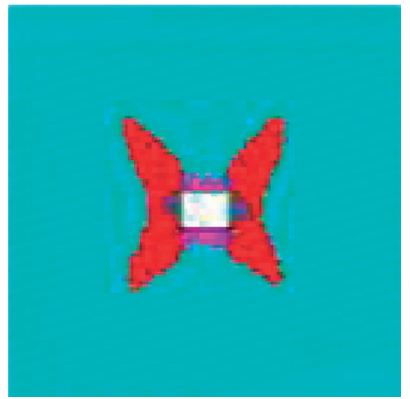

(d)

FIgURE 14: Morphology of plastic zone under different normal stiffness of bedding surface. (a) $5 e 9 \mathrm{MPa} \cdot \mathrm{cm}^{-1} \cdot(\mathrm{b}) 10 e 9 \mathrm{MPa} \cdot \mathrm{cm}^{-1}$. (c) $15 e 9 \mathrm{MPa} \cdot \mathrm{cm}^{-1}$. (d) $20 e 9 \mathrm{MPa} \cdot \mathrm{cm}^{-1}$.

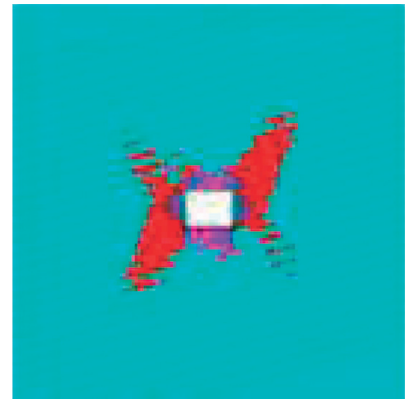

(a)

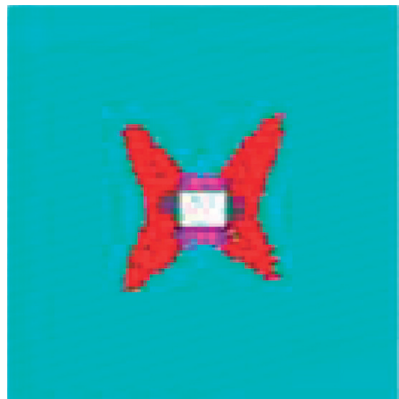

(b)

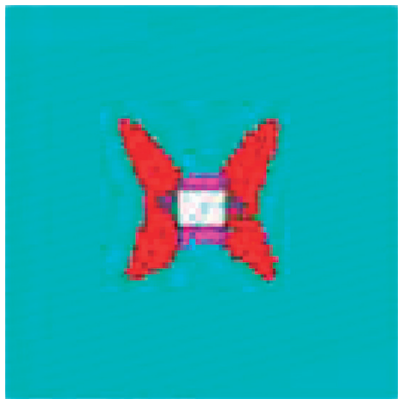

(c)

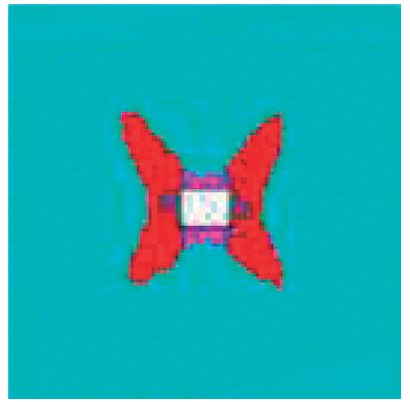

(d)

Figure 15: Morphology of plastic zone under different shear stiffness of bedding surface. (a) $0.5 e 9 \mathrm{MPa} \cdot \mathrm{cm}^{-1}$. (b) $2.5 e 9 \mathrm{MPa} \cdot \mathrm{cm}^{-1}$. (c) $4.5 e 9 \mathrm{MPa} \cdot \mathrm{cm}^{-1}$. (d) $6.5 e 9 \mathrm{MPa} \cdot \mathrm{cm}^{-1}$.

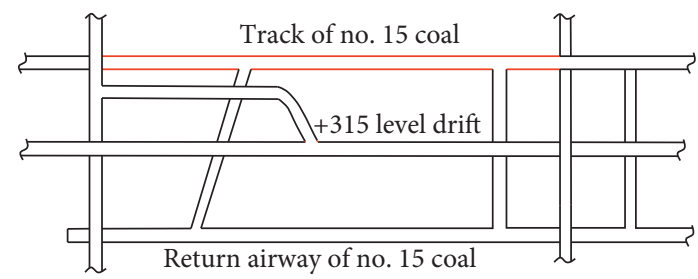

Figure 16: Roadway layout of face No. 603.

From Figure 20, the crack development area can be divided into severe crack area, moderate crack area, and mild crack area along the roadway surface to deep. The outline connecting lines of these three areas are approximately saddleshaped. The maximum values of the severe crack area at the two sides, the shoulder corners, and the middle of the roof are $1.7 \mathrm{~m}, 3.4 \mathrm{~m}$, and $1.3 \mathrm{~m}$, respectively. The maximum values of the mild crack area at the two sides, the shoulder corners, and the middle of the roof are $6.5 \mathrm{~m}, 10.2 \mathrm{~m}$, and $5.7 \mathrm{~m}$, respectively. This shows that the destruction depth of the surrounding rock is not the same in different distribution intervals, which directly leads to an increase in the intensity of the deformation of the surrounding rock in different parts. The contour line is consistent with the contour line of the plastic zone when the side pressure ratio is $1: 3$. In particular, the positions of the shoulders of the roadway are like butterfly leaves. The following phenomena exist in the roadway surrounding rock failure zone: shoulder corner $>$ two sides $>$ roof.

\begin{tabular}{|c|c|c|}
\hline Name of rock & $\begin{array}{l}\text { Stratigraphic } \\
\text { column }\end{array}$ & Average thickness (m) \\
\hline Mudstone & & $3.0 \mathrm{~m}$ \\
\hline Siltstone & & $2.8 \mathrm{~m}$ \\
\hline $\begin{array}{l}\text { Sandy } \\
\text { mudstone }\end{array}$ & 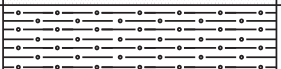 & $3.0 \mathrm{~m}$ \\
\hline Limestone $\mathrm{K}_{2}$ & 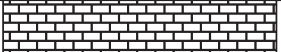 & $2.85 \mathrm{~m}$ \\
\hline Coal seam $15 \#$ & & $4.15 \mathrm{~m}$ \\
\hline lnterband coal & & $1.6 \mathrm{~m}$ \\
\hline $\begin{array}{c}\text { Sandy } \\
\text { mudstone }\end{array}$ & 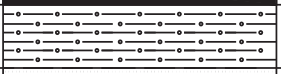 & $3.57 \mathrm{~m}$ \\
\hline Siltstone & & $2.81 \mathrm{~m}$ \\
\hline Mudstone & 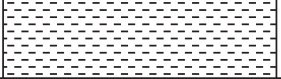 & $3.2 \mathrm{~m}$ \\
\hline
\end{tabular}

FIgURE 17: The bar graph of lithology of roadway surrounding rock.

4.3. Deformation Characteristics of the Roadway. The failure mechanism of the roadway can be further clarified by analyzing the plastic zone of the surrounding rock of the roadway. In order to clarify the deformation and failure 


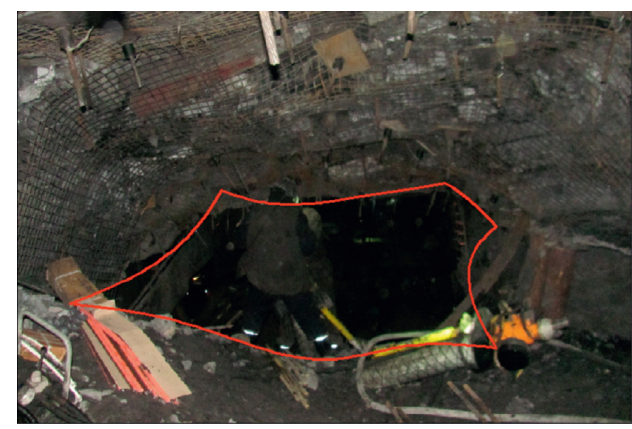

(a)

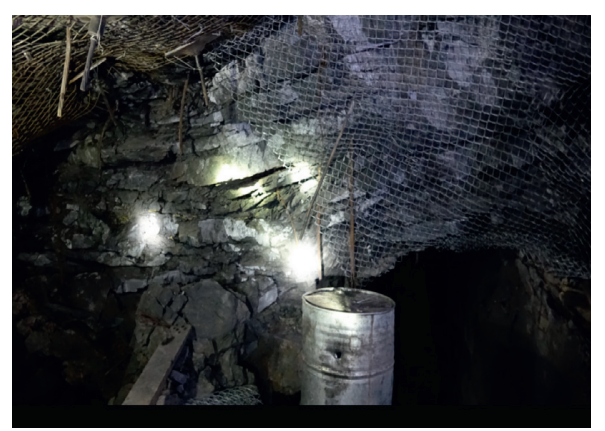

(b)

Figure 18: Deformation and failure of roadway surrounding rock. (a) Deformation and failure. (b) Layered joints.

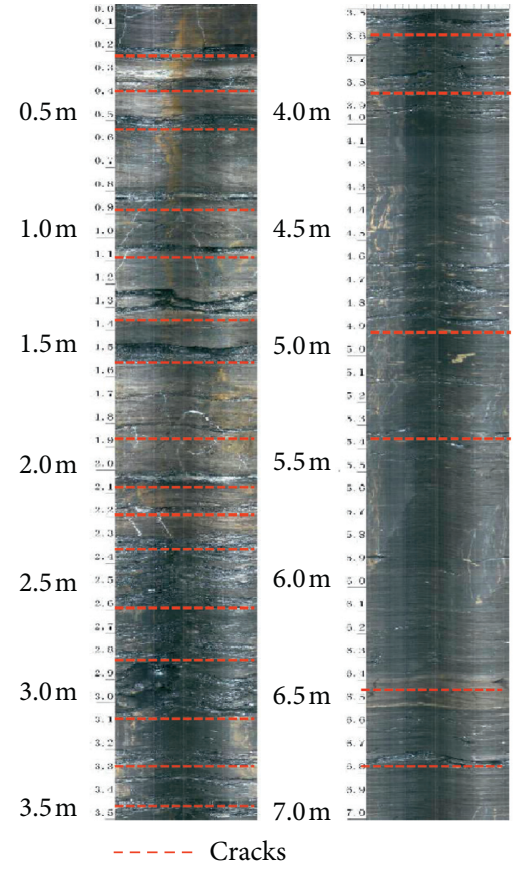

(a)

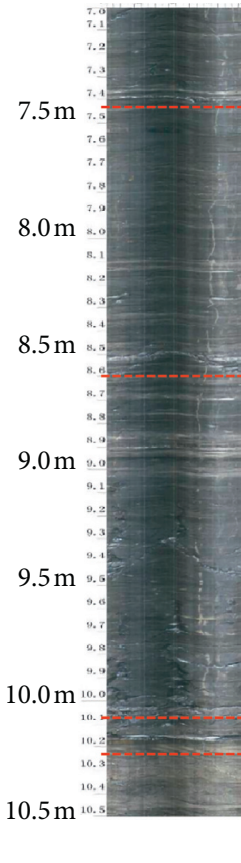

$3.5 \mathrm{~m}$

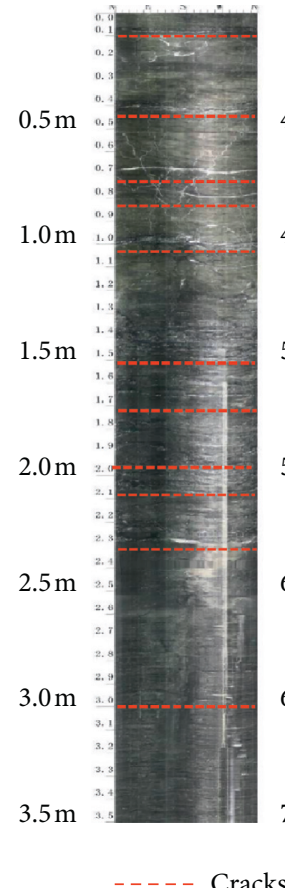

Cracks
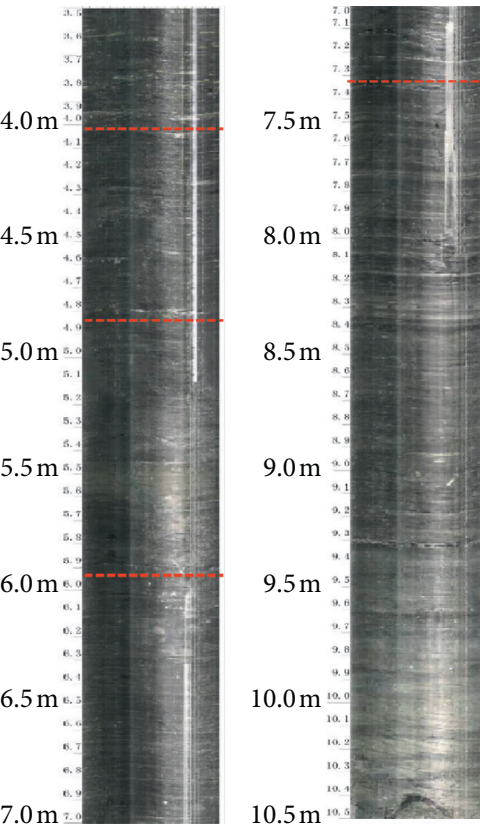

(b)

FIgURE 19: Continued. 


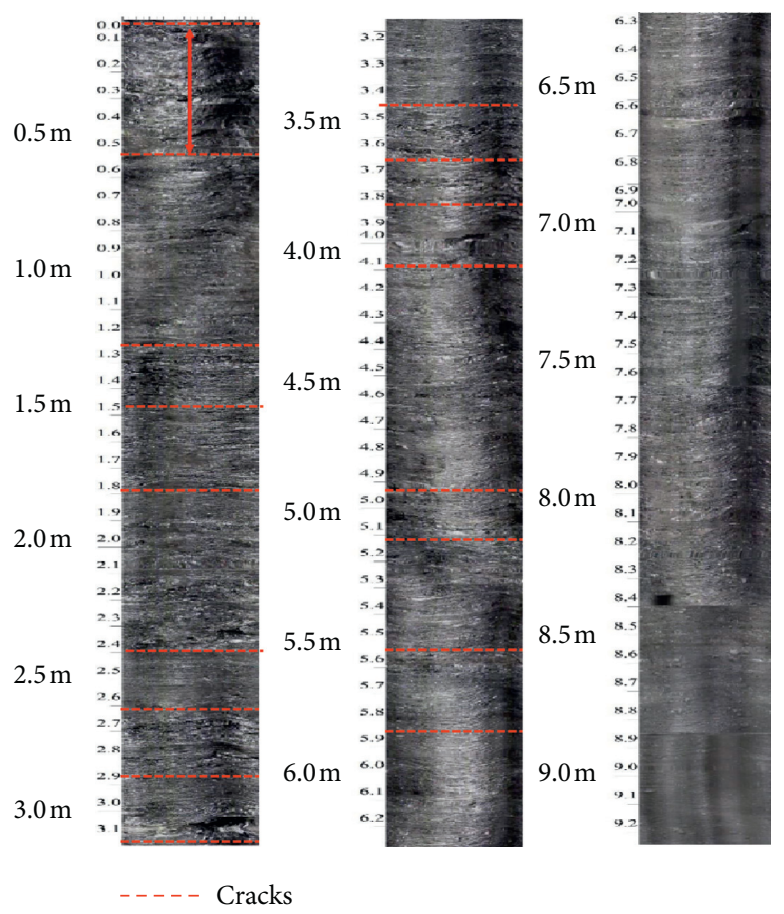

(c)

FIGURE 19: The typical borehole fracture images of surrounding rock in different depths. (a) The junction of the roof and the left sidewall. (b) The middle of roof. (c) The sidewall of roadway surrounding rock.

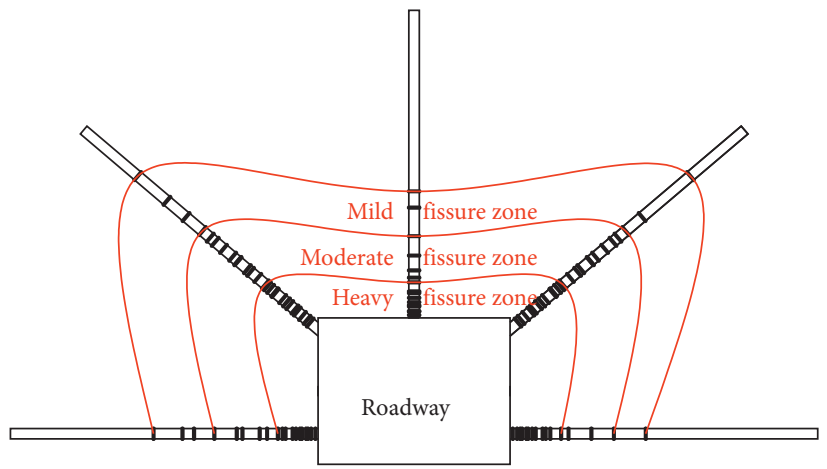

FIGURE 20: The observation result of surrounding rock deformation characteristics.

characteristics of surrounding rock of track roadway of coal seam No. 15, the numerical calculation model was reestablished. The coal seam inclination angle of $8^{\circ}$ belongs to the near horizontal coal seam, so it was simplified to the horizontal state. The interface command in FLAC3D program was used to set up a total of 9 structural surfaces. The model sizes are length $\times$ width $\times$ height $=30 \mathrm{~m} \times 30 \mathrm{~m} \times 5 \mathrm{~m}$, the tunnel section sizes are length $\times$ width $=4 \times 3.8 \mathrm{~m}$, and the number of mesh divisions is between 50,000 and 60000 . The left, right, front, back, and bottom of the model are displacement boundaries and the upper stress boundaries. According to the measured mine pressure data and experience provided by the miner, the stress applied at the top of the model is $2500 \times 700 \mathrm{~m}=17.5 \mathrm{MPa}$, and the lateral pressure coefficient $\lambda=0.34$, as shown in Figure 21 .
According to the data in the rock mechanics manual and the mechanical parameters of the roof and floor provided by the miner, and combined with numerical simulation inversion, the mechanical parameters of the roadway roof and floor were obtained as shown in Table 2. Mechanical parameters of structural surfaces are consistent with those in Table 1.

According to the original support design drawing provided by the mining party, the numerical simulation support scheme design was carried out. The roof is supported by four rock bolts and three anchor cables, and the left sidewall and the right sidewall are supported by five rock bolts, respectively. The size of the rock bolt is $\varphi \times L=22 \mathrm{~mm} \times 2400 \mathrm{~mm}$, the size of the anchor cable is $\varphi \times L=17.8 \mathrm{~mm} \times 8300 \mathrm{~mm}$, and the preload forces of the bolt and anchor cable are $30 \mathrm{kN}$ 


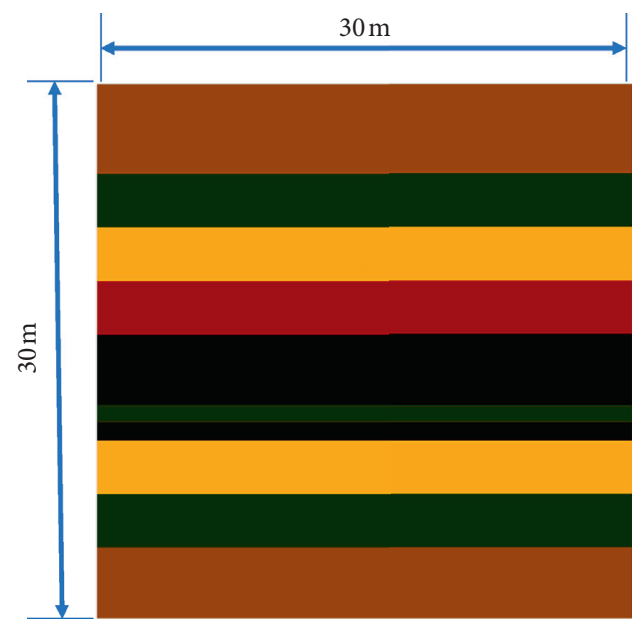

(a)

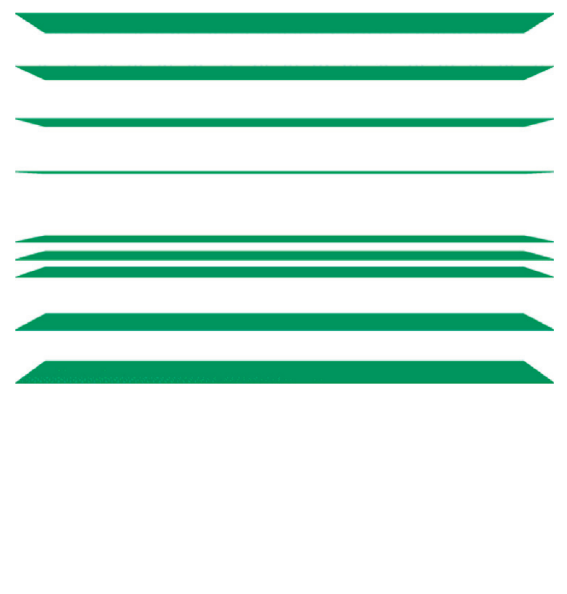

(b)

Figure 21: Model dimensions and bedding surfaces.

TABLE 2: Mechanical parameter of models.

\begin{tabular}{|c|c|c|c|c|c|c|}
\hline Group & $\begin{array}{l}\text { Bulk modulus } \\
\qquad(\mathrm{GPa})\end{array}$ & $\begin{array}{l}\text { Shear modulus } \\
(\mathrm{GPa})\end{array}$ & $\begin{array}{c}\text { Internal friction } \\
\text { angle }\left(^{\circ}\right)\end{array}$ & $\begin{array}{c}\text { Cohesion } \\
(\mathrm{MPa})\end{array}$ & $\begin{array}{l}\text { Density } \\
\left(\mathrm{kg} \cdot \mathrm{m}^{-3}\right)\end{array}$ & Tensile strength $(\mathrm{MPa})$ \\
\hline Mudstone & 2.17 & 1.41 & 36 & 1.5 & 2775 & 1.32 \\
\hline Siltstone & 3.47 & 2.08 & 41 & 4.3 & 2745 & 2.62 \\
\hline $\begin{array}{l}\text { Sandy } \\
\text { mudstone }\end{array}$ & 3.12 & 1.78 & 36 & 2.16 & 2530 & 2.25 \\
\hline Limestone $\mathrm{K}_{2}$ & 5.22 & 2.54 & 37 & 7.8 & 2800 & 4.21 \\
\hline Coal seam $15 \#$ & 0.87 & 0.48 & 30 & 1.26 & 1500 & 0.03 \\
\hline Interband coal & 0.81 & 0.42 & 30 & 1.16 & 2400 & 0.2 \\
\hline
\end{tabular}

and $65 \mathrm{kN}$, respectively. The rock bolt interval and row spacing are $800 \mathrm{~mm}$ and $700 \mathrm{~mm}$, respectively, and the anchor cable interval and row spacing are $1500 \mathrm{~mm}$ and $2000 \mathrm{~mm}$, respectively. The details are shown in Figure 22.

Figure 23 shows the failure mode of the plastic zone in the track roadway of coal seam No. 15. The butterfly leaf part of the plastic zone (shear failure) of the roadway develops obliquely at the four corners of the roadway due to the influence of the layered joint surface and the nonuniform stress field. Tension failure is dominant in the positive direction of the roof and floor, which is distributed in a regular triangle pattern. The depth of the plastic zone in the four corners of the surrounding rock is the largest and is accompanied by obvious bedding penetration phenomenon.

With the expansion of the plastic zone, the surrounding rock of the roadway begins to show four corners bulging, roof sinking, floor bulging, and so forth. According to the mechanism of the expansion of butterfly-shaped plastic zone and the failure of surrounding rock, it can be preliminarily considered that the failure of surrounding rock of the track roadway is mainly caused by layered joint surfaces and nonuniform stress field.

The displacement nephogram of \#15 haulage roadway is shown in Figure 24; large deformation of surrounding rock is the most obvious feature. The maximum displacements of the roof and bottom plate are $0.45 \mathrm{~m}$ and $1.13 \mathrm{~m}$, respectively, and the deformation of the left and right sides is about $0.48 \mathrm{~m}$. There is a positive correlation between the deformation of surrounding rock and the distribution of plastic zone. It can be seen that the deformation and failure of the surrounding rock of the roadway are very serious under the support of the original scheme, which has a good matching degree with the field situation in Figure 18.

The field measurement data of nearly 100 days were organized into deformation curves of surrounding rock, as shown in Figure 25. It can be seen from Figure 25 that the deformation of surrounding rock began to increase after 20 days, and the increase of deformation began to decrease after 60 days, but it still kept increasing. After 100 days, the deformation of surrounding rock reaches the maximum value during the monitoring period, and the maximum displacements of floor, roof, left wall, and right wall are $1.35 \mathrm{~m}, 0.71 \mathrm{~m}, 0.63 \mathrm{~m}$, and $0.51 \mathrm{~m}$, respectively. The numerical simulation results are consistent with the field measurement results, indicating that the deformation and failure of surrounding rock are closely related to the plastic zone distribution of surrounding rock. 


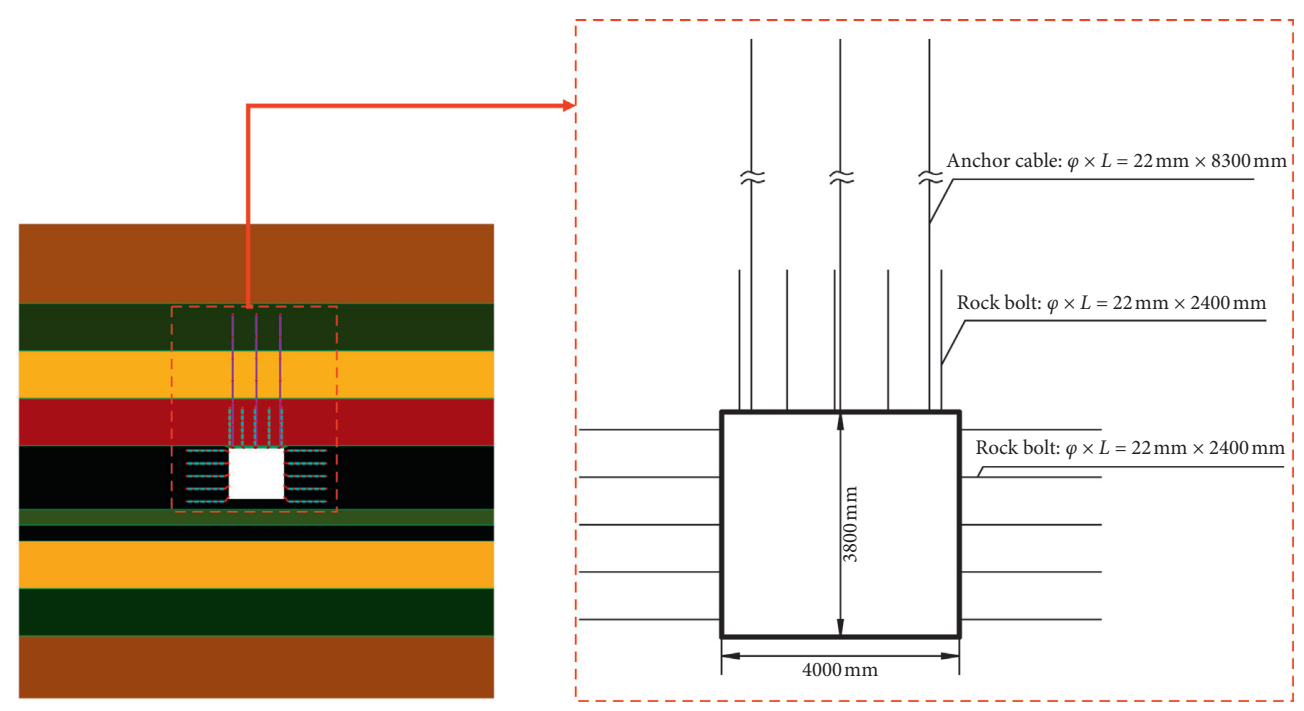

FIGURE 22: Support scheme design of numerical simulation.

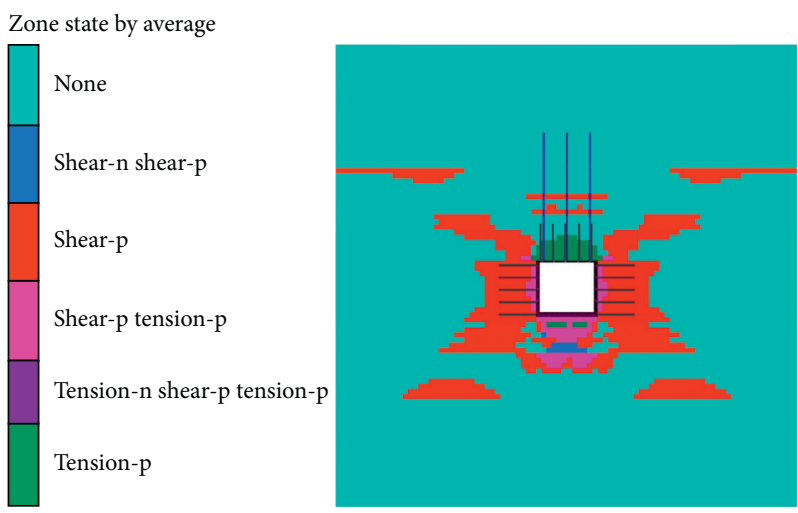

Figure 23: Plastic zone of \#15 haulage roadway.

Zone $Z$ displacement

$1.1296 E+00$
$1.0500 E+00$
$9.5000 E-01$
$8.5000 E-01$
$7.5000 E-01$
$6.5000 E-01$
$5.5000 E-01$
$4.5000 E-01$
$3.5000 E-01$
$2.5000 E-01$
$1.5000 E-01$
$5.0000 E-02$
$-5.0000 E-02$
$-1.5000 E-01$
$-2.5000 E-01$
$-3.5000 E-01$
$-4.5000 E-01$
$-4.5835 E-01$

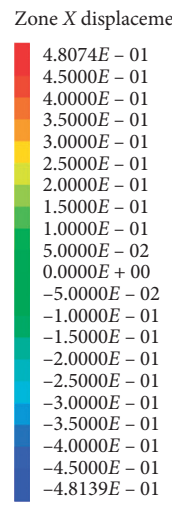

(a)

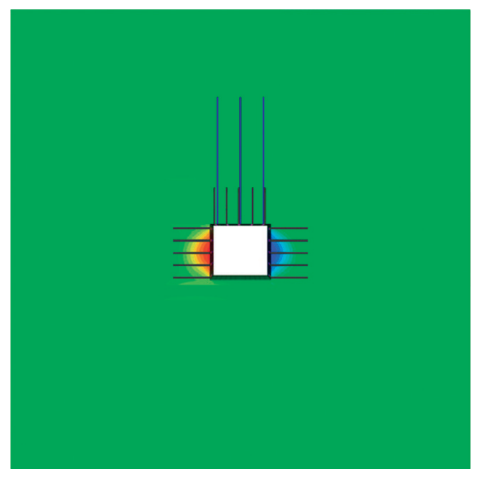

(b)

FIgURE 24: Numerical simulation of displacement nephogram of \#15 haulage roadway. 


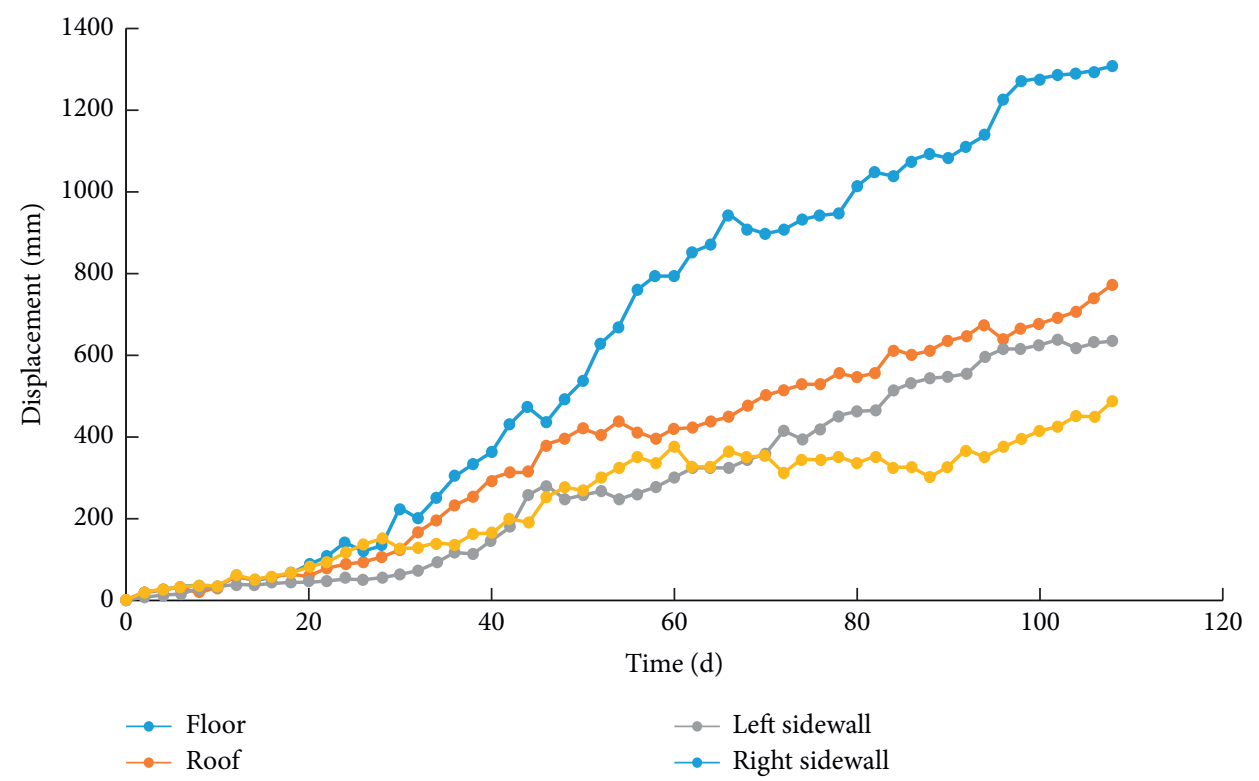

FIgURE 25: Measured displacement curve of \#15 haulage roadway.

\section{Conclusions}

It is of positive guiding significance to clarify the plastic zone distribution characteristics of surrounding rock in layered roadway for the study of surrounding rock deformation mechanism, support scheme design, roof accident treatment, and many other engineering practices. Some conclusions are summarized as follows:

(1) Based on the mechanical model and failure criterion of rock mass single structural plane, the failure conditions of rock mass are theoretically analyzed under different structural plane inclination angles. The uniaxial or triaxial compressive strength of the rock mass is controlled by the direction of loading and the inclination of the structural plane under a single structural plane. The strength of the rock mass is controlled by the angle between the maximum principal stress and the structural plane under a set of structural planes with the same properties.

(2) The shape of the area of maximum shear stress and minimum principal stress directly determines the shape of shear and tension failure in the plastic zone. The structure plane destroys the continuity of stress and strengthens the discreteness and laddering nature of stress.

(3) The horizontal structural plane has almost no effect on the plastic zone of the surrounding rock of the roadway. During the gradual increase of the structural plane inclination angle from $0^{\circ}$ to $90^{\circ}$, the overall shape of the plastic zone undergoes a process of decrease, increase, decrease, and increase again. When the inclination angle of the structural plane is $30^{\circ}$, the structural plane of the plastic zone is distributed in star-point shape and the overall dispersion is the strongest. When the inclination angle of the structural plane is $90^{\circ}$, the butterfly shape of the plastic zone is thinner and longer. The deformation of the surrounding rock of the roadway is affected by the shape and size of the plastic zone.

(4) Among many factors affecting the plastic zone of surrounding rock, only the lateral pressure coefficient can change the shape and size of the plastic zone of surrounding rock at the same time, the cohesion force and internal friction angle of rock strata can only change the size of plastic zone of surrounding rock, and the mechanical properties of bedding surface can change the size and dispersion degree of the plastic zone of surrounding rock.

(5) Different dip angles of bedding plane have obvious influence on the deformation and failure of surrounding rock, which is the joint action of dip angles of bedding surfaces, stress state, and mechanical properties of rock strata. When the angle $\beta$ between the maximum principal stress and bedding surfaces is closer to $\pi / 4+b_{j} / 2\left(b_{j}\right.$ is the internal friction angle of bedding surface), the deformation and failure of surrounding rock are more influenced by the bedding plane. When the angle $\beta$ between the maximum principal stress and bedding plane is closer to $\pi / 2$, the deformation and failure of surrounding rock are less influenced by the bedding plane.

(6) The deformation characteristics of the track roadway of coal seam No. 15 are analyzed by using the expansion theory of butterfly plastic zone and the expansion characteristics of layered roadway surrounding rock plastic zone. The research results show that the track roadway of coal seam No. 15 belongs to a typical failure form under the influence of asymmetric high stress and layered surrounding rock mass. 


\section{Data Availability}

The data used to support the findings of this study are available from the corresponding author upon request.

\section{Conflicts of Interest}

The author declares that there are no conflicts of interest.

\section{Authors' Contributions}

All the research contents of this paper were independently completed by Yongxin Sun.

\section{Acknowledgments}

This work was financially supported by the General Project of CCTEG Coal Mining Research Institute (Grant no. 2020KCMS03).

\section{References}

[1] H. Kang, "Seventy years development and prospects of strata control technology for coal mine roadways in China," Chinese Journal of Rock Mechanics and Engineering, vol. 40, pp. 1-30, 2021, in Chinese.

[2] Z. Liang, W. Song, and W. Liu, "Theoretical models for simulating the failure range and stability of inclined floor strata induced by mining and hydraulic pressure," International Journal of Rock Mechanics and Mining Sciences, vol. 132, Article ID 104382, 2020.

[3] H. Manchao, Y. Peng, S. Zhao et al., "Fracture mechanism of inversed trapezoidal shaped tunnel excavated in $45^{\circ}$ inclined rock strata," International Journal of Mining Science and Technology, vol. 25, no. 4, pp. 531-535, 2015.

[4] W. Tan, P. H. S. W. Kulatilake, and H. Sun, "Influence of an inclined rock stratum on in-situ stress state in an open-pit mine," Geotechnical and Geological Engineering, vol. 32, no. 1, pp. 31-42, 2014.

[5] J. Zhang, L. Wang, Q. Li, and S. Zhu, "Plastic zone analysis and support optimization of shallow roadway with weakly cemented soft strata," International Journal of Mining Science and Technology, vol. 25, no. 3, pp. 395-400, 2015.

[6] M. Njie, L. Ji, and Z. Zhao, "Distribution of the deviatoric stress field and plastic zone in circular roadway surrounding rock," Journal of China University of Mining \& Technology, vol. 44, no. 2, pp. 206-213, 2015, in Chinese.

[7] W. Wang, E. Dong, and C. Yuan, "Boundary equation of plastic zone of circular roadway in non-axisymmetric stress and its application," Journal of China Coal Society, vol. 44, no. 1, pp. 105-114, 2019, in Chinese.

[8] Y. Sun, G. Li, J. Zhang et al., "Stability control for the rheological roadway by a novel high-efficiency jet grouting technique in deep underground coal mines," Sustainability, vol. 11, 2019.

[9] H. Kastner, Statik Des Tunnel-Und Stollenbaues, SpringerVerlag, Berlin, Heidelberg, Germany, 1971.

[10] R. E. Goodman, "An introduction to rock mechanics," Engineering Geology, vol. 19, no. 1, pp. 72-74, 1980.

[11] A. H. Wilson, "A method of estimating the closure and strength of lining required in drivages surrounded by a yield zone," International Journal of Rock Mechanics and Mining
Sciences \& Geomechanics Abstracts, vol. 17, no. 6, pp. 349-355, 1980.

[12] E. T. Brown, J. W. Bray, B. Ladanyi, and E. Hoek, "Ground response curves for rock tunnels," Journal of Geotechnical Engineering, vol. 109, no. 1, pp. 15-39, 1983.

[13] N. Ma, J. Li, and Z. Zhao, "Distribution of the deviatoric stress field and plastic zone in circular roadway surrounding rock," Journal of China University of Mining \& Technology, vol. 44, no. 2, pp. 206-213, 2015, in Chinese.

[14] N. Ma and C. Hou, "A research into plastic zone of surrounding strata of gate way affected by mining abutment stress," in Proceedings of the 32nd U.S. Symposium on Rock Mechanics, Norman, OklahomaJuly 1990, in Chinese.

[15] Q.-b. Meng, "Numerical simulation of cross-section shape optimization design of deep soft rock roadway under high stress," Journal of Mining \& Safety Engineering, vol. 29, no. 5, pp. 651-654, 2012, in Chinese.

[16] Z. Zhao, N. Ma, H. Liu, and X. Guo, "A butterfly failure theory of rock mass around roadway and its application prospect," Journal of China University of Mining \& Technology, vol. 47, no. 5, pp. 969-978, 2018, in Chinese.

[17] W. Wang, G. y. Guo, Y. Zhu et al., "Malignant expansion process and control of plastic zone surrounding rock of high stress soft rock Roadway," Journal of China Coal Society, vol. 255, no. 12, pp. 5-12, 2015, in Chinese.

[18] C. Li, J. Xu, J. z. Pan, and C. Ma, "Plastic zone distribution laws and its types of surrounding rock in large-span roadway," International Journal of Mining Science and Technology, vol. 22, no. 1, pp. 23-28, 2012.

[19] W. Yin, Y. Pan, and Z. Li, "Study on critical conditions of rock burst under circular ductility considering deterioration of strength parameters in plastic zone," Chinese Journal of Coal, vol. 43 , no. 2 , pp. $348-355,2018$, in Chinese.

[20] H. Liu, Z. Ho, X. Wu, X. Zhao, L. Guo, and Z. Ma, "Mechanism of shock disaster induced by transient malignant expansion in plastic zone," Chinese Journal of Coal, pp. 1392-1399, 2017, in Chinese.

[21] C. C. Li, "A new energy-absorbing bolt for rock support in high stress rock masses," International Journal of Rock Mechanics and Mining Sciences, vol. 47, no. 3, pp. 396-404, 2010.

[22] H. X. Jia, G. Li, L. Wang, and A. Qiao, "Study on environmental characteristics and roof falling mechanism of mining roadway stress field," Journal of Mining \&Safety Engineering, vol. 34, no. 4, pp. 707-714, 2017.

[23] M. R. Zareifard and A. Fahimifar, "Analytical solutions for the stresses and deformations of deep tunnels in an elastic-brittleplastic rock mass considering the damaged zone," Tunnelling and Underground Space Technology, vol. 58, pp. 186-196, 2016. 